\title{
CREB Family Transcription Factors Are Major Mediators of BDNF Transcriptional Autoregulation in Cortical Neurons
}

\author{
Eli-Eelika Esvald, ${ }^{1,3 *}$ Jürgen Tuvikene, ${ }^{1,3 *}$ Alex Sirp, ${ }^{1}$ Sudarshan Patil, ${ }^{2}$ CClive R. Bramham, ${ }^{2}$ and Tõnis Timmusk ${ }^{1,3}$ \\ ${ }^{1}$ Department of Chemistry and Biotechnology, Tallinn University of Technology, Tallinn 12618, Estonia, ${ }^{2}$ Department of Biomedicine and KG Jebsen Centre \\ for Neuropsychiatric Disorders, University of Bergen, 5009 Bergen, Norway, and 3Protobios LLC, Tallinn 12618, Estonia
}

BDNF signaling via its transmembrane receptor TrkB has an important role in neuronal survival, differentiation, and synaptic plasticity. Remarkably, BDNF is capable of modulating its own expression levels in neurons, forming a transcriptional positive feedback loop. In the current study, we have investigated this phenomenon in primary cultures of rat cortical neurons using overexpression of dominantnegative forms of several transcription factors, including CREB, ATF2, C/EBP, USF, and NFAT. We show that CREB family transcription factors, together with the coactivator $\mathrm{CBP} / \mathrm{p} 300$, but not the CRTC family, are the main regulators of rat $B D N F$ gene expression after TrkB signaling. CREB family transcription factors are required for the early induction of all the major BDNF transcripts, whereas CREB itself directly binds only to $B D N F$ promoter IV, is phosphorylated in response to BDNF-TrkB signaling, and activates transcription from $B D N F$ promoter IV by recruiting CBP. Our complementary reporter assays with $B D N F$ promoter constructs indicate that the regulation of $B D N F$ by CREB family after BDNF-TrkB signaling is generally conserved between rat and human. However, we demonstrate that a nonconserved functional cAMP-responsive element in BDNF promoter IXa in humans renders the human promoter responsive to BDNF-TrkBCREB signaling, whereas the rat ortholog is unresponsive. Finally, we show that extensive BDNF transcriptional autoregulation, encompassing all major BDNF transcripts, occurs also in vivo in the adult rat hippocampus during BDNF-induced LTP. Collectively, these results improve the understanding of the intricate mechanism of BDNF transcriptional autoregulation.

Key words: BDNF; CBP; CREB; positive feedback loop; transcription; TrkB

Significance Statement

Deeper understanding of stimulus-specific regulation of $B D N F$ gene expression is essential to precisely adjust BDNF levels that are dysregulated in various neurological disorders. Here, we have elucidated the molecular mechanisms behind TrkB signalingdependent $B D N F$ mRNA induction and show that CREB family transcription factors are the main regulators of $B D N F$ gene expression after TrkB signaling. Our results suggest that BDNF-TrkB signaling may induce BDNF gene expression in a distinct manner compared with neuronal activity. Moreover, our data suggest the existence of a stimulus-specific distal enhancer modulating BDNF gene expression.

\section{Introduction}

BDNF is a widely expressed neurotrophin in the CNS that has been described to promote the survival and differentiation of

Received Feb. 14, 2019; revised Dec. 10, 2019; accepted Dec. 28, 2019.

Author contributions: E.-E.E., J.T., S.P., C.R.B., and T.T. designed research; E.-E.E., J.T., A.S., and S.P. performed research; E.-E.E., J.T., A.S., S.P., and T.T. analyzed data; E.-E.E. wrote the first draft of the paper; E.-E.E., J.T., S.P., C.R.B., and T.T. edited the paper; E.-E.E. and J.T. wrote the paper.

This work was supported by Estonian Research Council Institutional Research Funding IUT19-18 and Grant ETF8844; National R\&D Program Biotechnology Grant AR12030; European Union through the European Regional Development Fund Project 2014-2020.4.01.15-0012 and H2020-MSCA-RISE-2016 (EU734791); Estonian Enterprise Grant EU27553; Norwegian Financial Mechanism Grant EMP128; European Union Joint Programme-Neurodegenerative Disease Research project CircProt (funding to C.R.B. provided by the Research Council of Norway), and the Estonian Academy of Sciences. We thank Epp Väli and Maila Rähn for technical assistance; Priit Pruunsild and Ester Orav for contributions in the early stages of the project; Käthy Rannaste for cloning and testing the functionality of CRTC1 gRNA constructs; and Priit Pruunsild for critical reading of the manuscript.

The authors declare no competing financial interests. neurons and induce neurite outgrowth in the development of the brain (Bibel and Barde, 2000; Huang and Reichardt, 2001; Park and Poo, 2013). In the adult brain, the main function of BDNF is to enhance synaptic transmission, facilitate synaptic plasticity, and promote synaptic growth (Bramham and Messaoudi, 2005; Minichiello, 2009; Lu et al., 2013, 2014; Park and Poo, 2013). For example, BDNF signaling is important for synaptic consolidation (Wibrand et al., 2006; Panja et al., 2014) and memory consolidation (Bambah-Mukku et al., 2014). In addition, BDNF signaling

${ }^{*}$ E.-E.E. and J.T. contributed equally to this work

Correspondence should be addressed to Tõnis Timmusk at tonis.timmusk@taltech.ee or Eli-Eelika Esvald at eli-eelika.esvald@taltech.ee.

https://doi.org/10.1523/JNEUROSCI.0367-19.2019

Copyright $\odot 2020$ the authors 
in adult brain is involved in neurogenesis and dendrite formation of hippocampal granule neurons (Wang et al., 2015; Vilar and Mira, 2016).

$B D N F$ gene expression is regulated in a sophisticated manner, with the transcription of every $5^{\prime}$ exon being controlled by a separate promoter (Timmusk et al., 1993; Aid et al., 2007; Pruunsild et al., 2007) and by numerous transcription factors (e.g., NPAS4, USF family, MeCP2, NFAT family, and CREB) in response to various stimuli (for review, see West et al., 2014). Interestingly, disruption of specific $B D N F$ transcripts has proven important roles for different $B D N F$ promoters in the formation of neural circuits underlying social behavior (Maynard et al., 2016, 2018).

The cAMP-response element-binding (CREB) family of transcription factors consists of three functionally redundant basicleucine zipper transcription factors, namely, CREB protein, activating transcription factor 1 (ATF1), and cAMP-response element modulator (CREM) (Mayr and Montminy, 2001). The role of CREB family in the CNS has been investigated thoroughly (for review, see Barco and Marie, 2011), and CREB family has been shown to support neuronal survival (Mantamadiotis et al., 2002), regulate neuronal migration (Díaz-Ruiz et al., 2008), modulate synaptogenesis (Aguado et al., 2009), and contribute to the formation of LTP and long-term memory (Bourtchuladze et al., 1994). The CREB family has two types of coactivators. First, CREB binding protein (CBP) and its paralogue p300 (Lundblad et al., 1995), which interact with Ser-133-phosphorylated CREB and function via histone acetyl transferase activity (Bannister and Kouzarides, 1996) or interaction with basal transcriptional machinery (Kwok et al., 1994; Kee et al., 1996). Second, the CREBregulated transcription coactivators (CRTC-s) that are localized in the cytoplasm, but in response to increase in cytoplasmic cAMP and $\mathrm{Ca}^{2+}$ levels can be dephosphorylated and transported to the nucleus (Bittinger et al., 2004) where they bind to the CREB leucine zipper domain to stabilize the CREB dimer (Luo et al., 2012; Song et al., 2018) and interact with general transcription factors (Conkright et al., 2003). The use of different coactivators allows for a differential activation of cAMP-responsive element (CRE)-containing promoters in response to diverse stimuli in different cell types.

BDNF can modulate its own mRNA expression via activation of the TrkB receptor and downstream MAPK signaling (Yasuda et al., 2007; Nakajima et al., 2015; Tuvikene et al., 2016). Furthermore, BDNF-TrkB signaling has been shown to induce the expression of all the $B D N F$ transcripts in cultured rat cortical neurons (Tuvikene et al., 2016) and BDNF exon IV-containing transcripts in the rat hippocampus in vivo (Wibrand et al., 2006; Bambah-Mukku et al., 2014). The induction of BDNF exon I-containing transcripts is directly, while BDNF exon III- and VI-containing transcripts are indirectly, regulated by AP-1 transcription factors after BDNF-TrkB signaling (Tuvikene et al., 2016). The induction of BDNF exon IV-containing transcripts is mediated by $\mathrm{C} / \mathrm{EBP} \beta$ after inhibitory avoidance training-induced BDNF-TrkB signaling (Bambah-Mukku et al., 2014). Still, the complete repertoire of transcription factors and cis-elements involved in BDNF transcriptional autoregulation has not been described. Here, we have investigated the molecular mechanism of BDNF transcriptional autoregulation in rat cortical neurons and show that CREB family transcription factors together with coactivator $\mathrm{CBP}$ are the main regulators of TrkB signalingdependent induction of all the major $B D N F$ transcripts.

\section{Materials and Methods}

Primary cultures of rat cortical neurons. All animal procedures were performed in compliance with the local ethics committee. Primary cultures of cortical neurons were generated from Sprague Dawley rat male and female pups at embryonic day 20-21. Cerebral cortices together with hippocampi were dissected and preserved in Leibovitz L15 media (PAA Laboratories) until further processing. Cortices and hippocampi were cut into small pieces and incubated in $1 \mathrm{ml} 0.25 \%$ Trypsin-EDTA $1 \times$ solution (Invitrogen) at $37^{\circ} \mathrm{C}$ for $10 \mathrm{~min}$. Next, final concentrations of $0.5 \mathrm{mg} / \mathrm{ml}$ DNase I (Roche Diagnostics) and $12 \mathrm{~mm} \mathrm{MgSO}_{4}$ were added, and the mixture was again incubated at $37^{\circ} \mathrm{C}$ for $10 \mathrm{~min}$. Then, $275 \mu \mathrm{l}$ of $1 \%$ trypsin inhibitor (Invitrogen), $110 \mu$ l of $10 \%$ BSA (Pan-Biotech), and $50 \mu \mathrm{l}$ DNase I (stock solution $5 \mathrm{mg} / \mathrm{ml}$, Roche Diagnostics) were added and tissue was triturated 5 times using $1 \mathrm{ml}$ pipette tip. After trituration, tissue suspension was diluted in $1 \times$ Hank's buffered salt solution and centrifuged at $200 \times g$ for $30 \mathrm{~s}$. Supernatant was transferred to a new tube and centrifuged again at $200 \times g$ for 6 min. Finally, the supernatant was removed, and precipitated cells were resuspended in growth medium containing prewarmed Neurobasal A (PAA Laboratories or Invitrogen), $1 \times$ B27 Supplement (Invitrogen), $100 \mathrm{U} / \mathrm{ml}$ penicillin and $0.1 \mathrm{mg} / \mathrm{ml}$ streptomycin (Invitrogen), or $100 \mu \mathrm{g} / \mathrm{ml}$ Primocin (InvivoGen), $1 \mathrm{~mm}$ L-glutamine (Invitrogen). Cell suspension was distributed to plates previously coated with $0.2 \mathrm{mg} / \mathrm{ml}$ poly-L-lysine (Sigma Millipore) in $0.1 \mathrm{M}$ borate buffer overnight at $4^{\circ} \mathrm{C}$ or at least $1 \mathrm{~h}$ at room temperature. Cells were grown at $37^{\circ} \mathrm{C}$ in $5 \% \mathrm{CO}_{2}$ atmosphere. At $2 \mathrm{DIV}$, half of the growth medium, or the whole media when the neurons were transduced with lentiviral particles, was changed and a final concentration of $10 \mu \mathrm{M} \mathrm{mi-}$ totic inhibitor 5-fluoro-2' -deoxyuridine (Sigma Millipore) was added.

Neurons were transduced with lentiviral particles at 0 DIV, or with adeno-associated viral (AAV) vectors at 2 DIV after medium change at $>3$ multiplicity of infection. The cells were treated at 7-8 DIV with 50 ng/ml BDNF (Peprotech), $20 \mu \mathrm{g} / \mathrm{ml}$ cycloheximide (CHX, Tocris Bioscience), or $5 \mu \mathrm{M}$ CBP-CREB interaction inhibitor (CCII, catalog \#217505, lot 2758191, Merck Millipore). Control cells were treated with respective volume of vehicle (DMSO or water). For the lentivirus-mediated overexpression of E1A, neurons were transduced at 5 DIV, $72 \mathrm{~h}$ before lysing the cells after BDNF treatment, as prolonged overexpression of E1A led to neuronal death.

Viral vectors. The plasmids containing dominant-negative inhibitory protein coding sequences were obtained from Addgene: CMV500 A-CREB (plasmid \#33371), CMV500 A-C/EBP (plasmid \#33352), CMV500 A-C/ EBP $\beta$ (plasmid \#33363), CMV500 A-ATF2 (plasmid \#33362), CMV566 A-USF (plasmid \#33360), and GFP-VIVIT (plasmid \#11106). The respective coding sequences were cloned to pAAV vector (AAV HelperFree System, Agilent Technologies) under the control of human Synapsin I promoter. For A-USF, HA-tag was replaced with FLAG-tag. The coding sequences used for overexpression are listed in Tuvikene, 2018. Production of AAV particles and estimation of viral titer were performed as described previously (Koppel et al., 2015).

Lentivirus transfer plasmid pLV-hU6-sgRNA-hUbC-dCas9-KRABT2A-GFP coding for repressive dCas9-KRAB was obtained from Addgene (plasmid \#71237), from which the gRNA expression cassette was removed using PacI restriction enzyme (Thermo Fisher Scientific). Specific guide RNA (gRNA) targeting sequences (Tuvikene, 2018) were designed using the Benchling Platform and cloned into pRRL-U6-gRNAhPGK-EGFP lentiviral plasmid, where the expression of gRNA is under the control of U6 promoter and EGFP is under the control of human PGK promoter. Cloned plasmids were transformed into STBL3 competent cells (Invitrogen) and purified from bacteria using PureLink HiPure Plasmid Midiprep Kit (Invitrogen). Finally, all gRNA plasmids were verified by sequencing. For overexpressing EGFP, A-CREB, E1A, and dominant-negative CRTC, the respective coding regions (Tuvikene, 2018) were cloned into pRRL vector under the control of human PGK promoter, with A-CREB, E1A, and dominant-negative CRTC having an $\mathrm{N}$-terminal FLAG-tag. Production of lentiviral particles was performed as described by Koppel et al. (2018). Relative titers of lentiviral particles were estimated by measuring provirus incorporation using qPCR. For further experiments, equal amounts of functional viral particles were 
used to transduce neurons, and $>95 \%$ transduction efficiency was verified by EGFP expression.

$R N A$ extraction and $q R T-P C R$. For RNA extraction, the neurons were lysed at 7-8 DIV in RLT lysis buffer and RNA was purified using RNeasy Mini Kit (QIAGEN) with on-column digestion of genomic DNA using RNase-Free DNase Set (QIAGEN). Concentrations of the purified RNAs were determined with BioSpec-nano spectrophotometer (Shimadzu). An equal amount of RNA within an experiment was taken for complementary DNA (cDNA) synthesis using SuperScript III Reverse Transcriptase (Thermo Fisher Scientific) or SuperScript IV Reverse Transcriptase (Thermo Fisher Scientific). qPCR was performed using LightCycler 480 SYBR Green I Master kit (Roche Diagnostics) or HOT FIREPol EvaGreen qPCR Mix Plus (Solis BioDyne) and LightCycler 480 Instrument II (Roche Diagnostics). Primers and annealing temperatures are listed in Tuvikene, 2018. All mRNA expression levels were normalized to HPRT1 expression levels. Data were log-transformed, meancentered and autoscaled as suggested by Willems et al. (2008) before statistical analysis.

Luciferase reporter assay. Plasmids containing different rat $B D N F$ $(\mathrm{r} B D N F)$ and human BDNF ( $\mathrm{h} B D N F)$ promoters $(\mathrm{p})$ have been described previously as follows: pGL4.15 rBDNF pI (Pruunsild et al., 2011), pGL4.15 rBDNF pIV and pGL4.15 rBDNF pIV CRE site mutant (Koppel and Timmusk, 2013), pGL4.15 rBDNF pIII and pGL4.15 rBDNF pVI (Tuvikene et al., 2016); pGL4.15 hBDNF pI 5', pGL4.15 hBDNF pIV, pGL4.15 hBDNF pIXa, and respective CRE site mutants (Pruunsild et al., 2011). pGL4.29 CRE reporter construct (Promega, \#9PIE847) was used as a positive control. $\mathrm{r} B D N F \mathrm{pI} 5^{\prime}$ region was generated from pGL4.15 $\mathrm{r} B D N F$ pI plasmid. $\mathrm{r} B D N F$ pII and pIXa sequences were generated from rat genomic DNA using Phusion Hot Start II DNA Polymerase (Thermo Fisher Scientific), and respective regions were cloned into pGL4.15 vector (Promega) in front of Firefly luciferase coding sequence and verified by sequencing. CRE site mutagenesis in $\mathrm{r} B D N F \mathrm{pI}$ and $\mathrm{pI} 5^{\prime}$ was performed as published by Pruunsild et al. (2011). The genomic coordinates of BDNF proximal promoter regions and respective CRE site mutations used in the reporter constructs are shown in Tuvikene, 2018.

Cultured neurons were transfected at 6 DIV on 48-well plate in duplicate wells using ratio of 1:2 of total DNA and Lipofectamine 2000 Reagent (Invitrogen). Per well, 250 ng of effector plasmid (pAAV-hSynI-EGFP or pAAV-hSynI-A-CREB), $250 \mathrm{ng}$ (or $500 \mathrm{ng}$ if no effector was used) of Firefly luciferase reporter plasmid, and 20 ng of mouse PGK/pGL4.83 plasmid expressing Renilla luciferase for normalization were transfected. At 7 or 8 DIV, as indicated in the figure legend, neurons were lysed in $1 \times$ Passive lysis buffer (Promega). Luciferase signal was measured with Dual-Glo Luciferase Assay System (Promega) using Genios Pro Multifunction Microplate Reader (Tecan Group).

For data analysis, Firefly luciferase signal was background-corrected and normalized to background-corrected Renilla luciferase signal. The averages of duplicate wells were calculated, data were log-transformed, and statistical analysis was performed. For CRE reporter experiments using CRTC1 knockdown and overexpression of dominant-negative CRTC, log-transformed data were also mean-centered and autoscaled before statistical analysis.

Western blot. Cultured neurons were lysed in $1 \times$ Laemmli buffer including 5\% $\beta$-mercaptoethanol. Proteins were separated using $10 \%$ SDS-PAGE and transferred to PVDF membrane (Merck Millipore) in Towbin buffer at $100 \mathrm{~V}$ for $100 \mathrm{~min}$ using Mini Trans-blot Cell system (Bio-Rad). The membrane was blocked in 5\% skimmed milk in TBST buffer ( $1 \times$ Tris-buffered saline, pH 7.4, and 0.1\% Tween 20; Amresco), and then incubated with primary antibody $\alpha$-CREB (1:1000, catalog \#06863, lot 2446851, Merck Millipore) and with secondary antibody goat anti-rabbit IgG conjugated with HRP (1:5000, Thermo Fisher Scientific) in $2 \%$ skimmed milk (AppliChem) in TBST at $4^{\circ} \mathrm{C}$ overnight and at room temperature for $1 \mathrm{~h}$, respectively. After both incubations, the membrane was washed 3 times with TBST for $5 \mathrm{~min}$ at room temperature. Chemiluminescence signal was produced with SuperSignal West Femto Maximum Sensitivity Substrate (Thermo Fisher Scientific), and the membrane was exposed to imaging system ImageQuant Las 4000 (GE Healthcare Life Sciences).
For reprobing, the membrane was stripped with warm $0.1 \mathrm{M}$ glycine solution, $\mathrm{pH} 2.0$, blocked again as described previously, and incubated with primary antibody $\alpha$-P-CREB (1:5000, catalog \#9198, lot 0010, Cell Signaling Technology) in 5\% BSA (Naxo) in TBST at $4^{\circ} \mathrm{C}$ overnight. Further procedure was performed as described previously. For loading control, the membrane was stained with Coomassie solution $(0.1 \%$ Coomassie Brilliant Blue R-250 Dye, 25\% ethanol, 7\% acetic acid) for $15 \mathrm{~min}$, followed by 2 washes with destaining solution (30\% ethanol, $10 \%$ acetic acid) for $5 \mathrm{~min}$ and rinsing with tap water. The membrane was imaged using ImageQuant Las 4000 (GE Healthcare Life Sciences).

CREB and P-CREB signals and total protein staining were quantified using densitometric analysis on ImageQuant TL software (GE Healthcare Life Sciences). CREB protein levels were normalized to total protein levels, and P-CREB protein levels were normalized to CREB protein levels. Data were log-transformed, mean-centered, and autoscaled; and statistical analysis was performed.

Immunocytochemistry. Immunocytochemistry was performed as described by Koppel et al. (2018) using CRTC1 antibody (1:1500, catalog \#2587, lot 3, Cell Signaling Technology) and goat anti-rabbit IgG conjugated with Alexa-488 (1:2000, Invitrogen) secondary antibody. Hoechst 33324 was used to visualize nuclei. Analysis was performed with LSM 510 META (Carl Zeiss). The specificity of the CRTC1 antibody in immunocytochemistry was verified using CRTC1 knockdown with CRISPR interference in neurons (data not shown).

Chromatin immunoprecipitation (ChIP). Cultured neurons were grown on $100 \mathrm{~mm}$ dishes; and at $7 \mathrm{DIV}$, the cell growth media was reduced to $5 \mathrm{ml}$ during BDNF treatment and proteins were crosslinked to DNA by adding $500 \mu \mathrm{l}$ crosslinking buffer ( $11 \%$ formaldehyde, $100 \mathrm{~mm}$ $\mathrm{NaCl}, 0.5$ mm EGTA, 50 mм HEPES, pH 8.0) and incubating at room temperature for $10 \mathrm{~min}$ for CREB and P-CREB ChIP. Crosslinking was stopped by adding final concentration of $0.12 \mathrm{M}$ glycine and incubating at room temperature for $10 \mathrm{~min}$. Subsequently, the cells were washed twice with $10 \mathrm{ml}$ ice-cold $1 \times \mathrm{PBS}$ and lysed in $500 \mu$ lysis solution (1\% SDS, 10 mM EDTA, $\mathrm{pH} 8.0,50 \mathrm{~mm}$ Tris- $\mathrm{HCl}, \mathrm{pH} 8.0,1 \times$ cOmplete protease inhibitor cocktail, Roche Diagnostics; $1 \times$ PhosSTOP phosphatase inhibitor cocktail, Roche Diagnostics) for 5 min on ice. Cells were collected with cell scraper and transferred to an Eppendorf tube where lysates were sonicated on ice using VCX-130 sonicator (Sonics) until an approximate average fragment size of $250-500 \mathrm{bp}$ was obtained. Following sonication, the lysates were centrifuged at $16000 \times g$ for $5 \mathrm{~min}$ at $4^{\circ} \mathrm{C}$, and supernatant was transferred to a new tube.

Protein concentration was determined using Pierce BCA Protein Assay Kit (Thermo Fisher Scientific); and where necessary, the concentrations were equalized using lysis buffer. Equal amounts of protein were diluted 9 times in dilution buffer ( $1 \%$ Triton X-100, $150 \mathrm{~mm} \mathrm{NaCl}, 2 \mathrm{~mm}$ EDTA, pH 8.0, 20 mm Tris- $\mathrm{HCl}, \mathrm{pH} 8.0,1 \times$ cOmplete protease inhibitor cocktail, Roche Diagnostics; $1 \times$ PhosSTOP phosphatase inhibitor cocktail, Roche Diagnostics). A total of $5 \mu \mathrm{g}$ of $\alpha$-CREB (catalog \#06-863, lot 2446851 , Merck Millipore) or $\alpha$-P-CREB (catalog \#9198, lot 0010, Cell Signaling Technology) was added to the diluted lysate and incubated overnight at $4^{\circ} \mathrm{C}$. In parallel, $50 \mu \mathrm{l}$ Dynabeads Protein G (Invitrogen) per immunoprecipitation reaction were washed twice with $1 \mathrm{ml}$ dilution buffer for $10 \mathrm{~min}$ at $4^{\circ} \mathrm{C}$ and blocked overnight at $4^{\circ} \mathrm{C}$ in $1 \mathrm{ml}$ dilution and lysis buffer solution (ratio of 9:1, respectively), containing $200 \mu \mathrm{g} / \mathrm{ml}$ BSA and $10 \mu \mathrm{g} / \mathrm{ml}$ salmon sperm DNA. The next day, the beads were washed twice with dilution buffer for $10 \mathrm{~min}$ at $4^{\circ} \mathrm{C}$ and finally diluted in dilution and lysis buffer solution (ratio of 9:1, respectively), distributed to samples, and incubated for $\sim 5 \mathrm{~h}$ with rotation at $4^{\circ} \mathrm{C}$. Then, the beads-antibody complexes were washed 4 times in $1 \mathrm{ml}$ wash buffer $(1 \%$ Triton X-100, 0.1\% SDS, $150 \mathrm{~mm} \mathrm{NaCl,} 2$ mм EDTA, pH 8.0, $20 \mathrm{~mm}$ Tris-HCl, $\mathrm{pH} 8.0,1 \times$ cOmplete protease inhibitor cocktail, Roche Diagnostics; $1 \times$ PhosSTOP phosphatase inhibitor cocktail, Roche Diagnostics) and once with final wash buffer (1\% Triton X-100, 0.1\% SDS, 500 mм NaCl, 2 mм EDTA, pH 8.0, 20 mm Tris-HCl, pH 8.0, $1 \times$ cOmplete protease inhibitor cocktail, Roche Diagnostics; $1 \times$ PhosSTOP phosphatase inhibitor cocktail, Roche Diagnostics) for $10 \mathrm{~min}$ per wash while rotating at $4^{\circ} \mathrm{C}$. DNA-protein complexes were eluted from the beads 3 times with $50 \mu$ l elution buffer ( $1 \%$ SDS, $100 \mathrm{~mm} \mathrm{NaHCO}_{3}, 1$ mм EDTA) at $37^{\circ} \mathrm{C}$ for $10 \mathrm{~min}$. The third elution was performed with an additional 
incubation at $65^{\circ} \mathrm{C}$ for $5 \mathrm{~min}$ before combining with other eluates. Input samples were diluted with elution buffer to a final volume of $150 \mu \mathrm{l}$. Crosslinking was reversed by adding final concentration of $250 \mathrm{mM} \mathrm{NaCl}$ and incubating at $65^{\circ} \mathrm{C}$ overnight.

The next day, $125 \mu \mathrm{g} / \mathrm{ml}$ RNase A was added to the samples and incubated at $37^{\circ} \mathrm{C}$ for at least $30 \mathrm{~min}$. After that, final concentrations of $6 \mathrm{~mm}$ EDTA and $240 \mu \mathrm{g} / \mathrm{ml}$ proteinase $\mathrm{K}$ were added and incubated at $45^{\circ} \mathrm{C}$ for at least $30 \mathrm{~min}$. Finally, genomic DNA was purified using QIAquick PCR Purification Kit (QIAGEN), and DNA enrichment was analyzed using qPCR. Primers and annealing temperatures are listed in Tuvikene, 2018. The efficiencies of primer pairs were determined using serial dilutions of input DNA. DNA enrichment was calculated relative to the respective DNA levels in input sample considering primer pair efficiency. For statistical analysis, data were log-transformed.

CBP ChIP followed the described protocol, except for the following modifications: crosslinking with formaldehyde was performed for 20 min; sonication was performed with BioRuptor Pico (Diagenode); 7.5-10 $\mu$ g of $\alpha$-CBP (catalog \#7389, lot 5, Cell Signaling Technology) antibody was used; phosphatase inhibitors were not used; washes with ice-cold solutions were performed quickly without rotation. For CBP ChIP, data were log-transformed and also mean-centered to account for variations in enrichment between different experiments.

Electrophysiology and intrahippocampal infusion of BDNF. Intrahippocampal BDNF infusion was performed as described previously (Ying et al., 2002; Messaoudi et al., 2007; Kuipers et al., 2016). All experiments were performed according to the ethical standards approved by the Norwegian Committee for Experiments on Animals. The experiments were performed on adult male rats of the Sprague Dawley strain (Taconic), weighing 250-350 g. Rats were anesthetized with urethane $(1.5 \mathrm{~g} / \mathrm{kg}$, i.p.), and positioned in a stereotaxic frame, while the body temperature was maintained at $37^{\circ} \mathrm{C}$ using thermostatically controlled electric heating pad. A concentric bipolar stimulating electrode (Tip separation $500 \mu \mathrm{m}$; SNEX 100; Rhodes Medical Instruments) was lowered into the angular bundle for stimulation of the medial perforant path. Stereotaxic coordinates for stimulation were as follows (in $\mathrm{mm}$ ): 7.9 posterior to bregma, 4.2 lateral to the midline, and 2.5 below the dura.

A Teflon-coated tungsten wire recording electrode (outer diameter of $0.075 \mathrm{~mm}$; A-M Systems \#7960) was glued to the infusion cannula (30 gauge). The electrode was then cut so that it extended $800 \mu \mathrm{m}$ from the end of the cannula. Stereotaxic coordinates for recording in the dentate hilus were as follows (in $\mathrm{mm}$ ): 3.9 posterior to bregma, 2.3 lateral, and $2.8-3.1$ below the dura. The recording electrode was slowly lowered into the dorsal hippocampus until a positive-going fEPSP of maximum slope was obtained in the dentate hilus. The tip of the infusion cannula was located in the deep striatum lacunosum-moleculare of field CA1, $800 \mu \mathrm{m}$ above the hilar recording site and 300-400 $\mu \mathrm{m}$ above the medial perforant synapses. The infusion cannula was connected via a polyethylene (PE50) tube to a $10 \mu \mathrm{l}$ Hamilton syringe and infusion pump. After baseline recording for $20 \mathrm{~min}$, the infusion of $2 \mu \mathrm{l}$ of $1 \mu \mathrm{g} / \mu \mathrm{l}$ BDNF (Alomone Labs) over $25 \mathrm{~min}$ at a rate of $0.08 \mu \mathrm{l} / \mathrm{min}$ followed. cytochrome $\mathrm{C}$ (CytC; Sigma Millipore) was used as a control for BDNF infusion. Evoked responses were recorded for $120 \mathrm{~min}$ after infusion.

Biphasic rectangular test pulses of $150 \mu$ s duration were applied every $30 \mathrm{~s}$ throughout the experiment $(0.033 \mathrm{~Hz})$. Responses were allowed to stabilize for $1 \mathrm{~h}$ at a stimulation intensity that produced a population spike $30 \%$ of maximum. A stable 20 min baseline of evoked potentials was recorded (pulse-width $0.15 \mathrm{~ms}$, at $0.033 \mathrm{~Hz}$ ) before intrahippocampal drug infusion. Evoked responses were recorded for $120 \mathrm{~min}$ after infusion. Signals from the dentate hilus were amplified, filtered $(0.1 \mathrm{~Hz}$ to $10 \mathrm{kHz})$, and digitized $(25 \mathrm{kHz})$. Acquisition and analysis of field potentials were accomplished using DataWave Technologies. The maximum slope of the fEPSP and the averages of four consecutive responses were obtained. Changes in the fEPSP slope were expressed in percentage of baseline (20 min preceding infusion). After recordings were completed, the electrodes were removed, rats were decapitated, and dentate gyri from both ipsilateral and contralateral hemisphere were dissected, immediately frozen on dry ice, and stored at $-80^{\circ} \mathrm{C}$. RNA was purified using RNeasy Lipid Tissue Mini Kit (QIAGEN), and qRT-PCR was performed as stated previously.

Statistical analysis and graphical representation of the data. Statistical analysis was performed on log-transformed, and where applicable, mean-centered and autoscaled data from independent experiments: neuron cultures obtained from different litters and prepared separately; or independent animals for the in vivo experiments. Two-tailed paired or unpaired $t$ tests, as indicated at each figure, were performed using Microsoft Excel 365. All tested hypotheses were specified before conducting the experiments. $p$ values were adjusted for multiple comparisons with Holm-Sidak family-wise error rate correction method using Prism 7.03 (GraphPad Software). For graphical representation, means and means \pm SEM of transformed data were calculated and data were backtransformed to linear scale with error bars indicating upper and lower limits of back-transformed mean \pm SEM.

\section{Results \\ BDNF transcriptional autoregulation requires protein synthesis}

Currently, only AP-1 and $\mathrm{C} / \mathrm{EBP} \beta$ transcription factors have been shown to be involved in BDNF transcriptional autoregulation in neurons. To extend the understanding of BDNF transcriptional autoregulation, we decided to perform a thorough analysis of additional transcription factors involved. We first asked whether the transcription factors that regulate BDNF expression in primary cultures of cortical neurons are synthesized in response to BDNF-TrkB signaling (like the AP-1 proteins) or are present in the cell before activation of TrkB signaling. Therefore, we treated cultured rat cortical neurons with the protein synthesis inhibitor CHX before BDNF treatment and measured the expression levels of different BDNF transcripts using qRTPCR (Fig. 1).

First, as a positive control of CHX treatment, we determined the expression levels of $c$-Fos, as it is known that the induction of $c$-Fos mRNA is largely independent of protein synthesis (Greenberg et al., 1986; Hughes et al., 1993). In cells pretreated with CHX, $1 \mathrm{~h}$ of BDNF treatment induced $c$-Fos expression level $\sim 24$-fold ( $p=0.0006$ ), and the expression levels remained high for $3 \mathrm{~h}(\sim 31$-fold, $p=0.0056)$ and $6 \mathrm{~h}(\sim 14$-fold, $p=0.0116)$ of BDNF treatment (Fig. 1). Next, we measured the induction of $B D N F$ mRNA levels after BDNF-TrkB signaling. Without disrupting protein synthesis, the induction of total BDNF mRNA was $\sim 3.6$-fold ( $p=0.0737$ ) after $1 \mathrm{~h}, \sim 13$-fold ( $p=0.0034)$ after $3 \mathrm{~h}$ and $\sim 6.7$-fold ( $p=0.0152$ ) after $6 \mathrm{~h}$ of BDNF-TrkB signaling. Blocking protein synthesis reduced the induction of total $B D N F$ mRNA to $\sim 1.8$-fold ( $p=0.0325$ ) after $1 \mathrm{~h}$, to $\sim 1.6$-fold $(p=0.2899)$ after $3 \mathrm{~h}$ of BDNF treatment, and after $6 \mathrm{~h}$ of BDNF treatment the expression levels were approximately similar to the expression levels in cells not treated with BDNF. At different transcript level, blocking protein synthesis completely abolished the TrkB signaling-dependent induction of BDNF exon I-, III-, and IXa-containing transcripts. In contrast, the early induction of BDNF exon IV-containing transcripts remained after $\mathrm{CHX}$ treatment, in which case after $1 \mathrm{~h}$ of BDNF treatment a $\sim 2.8$-fold $(p=0.0035)$ induction was still observed, while the induction in cells not treated with $\mathrm{CHX}$ at the respective time point was $\sim 6.3$ fold ( $p=0.0618)$. In CHX-treated cells, we also observed a minor $\sim 1.4$-fold $(p=0.0379)$ and $\sim 1.3$-fold $(p=0.0417)$ induction of $B D N F$ exon IIc- and VI-containing transcripts, respectively, after $1 \mathrm{~h}$ of BDNF treatment, while the induction of these transcripts in cells not treated with $\mathrm{CHX}$ at the same time point was $\sim 1.6$-fold ( $p=0.2181)$ and $\sim 1.8$-fold ( $p=0.0845)$, respectively. Together, our results indicate that at least some transcription factors neces- 

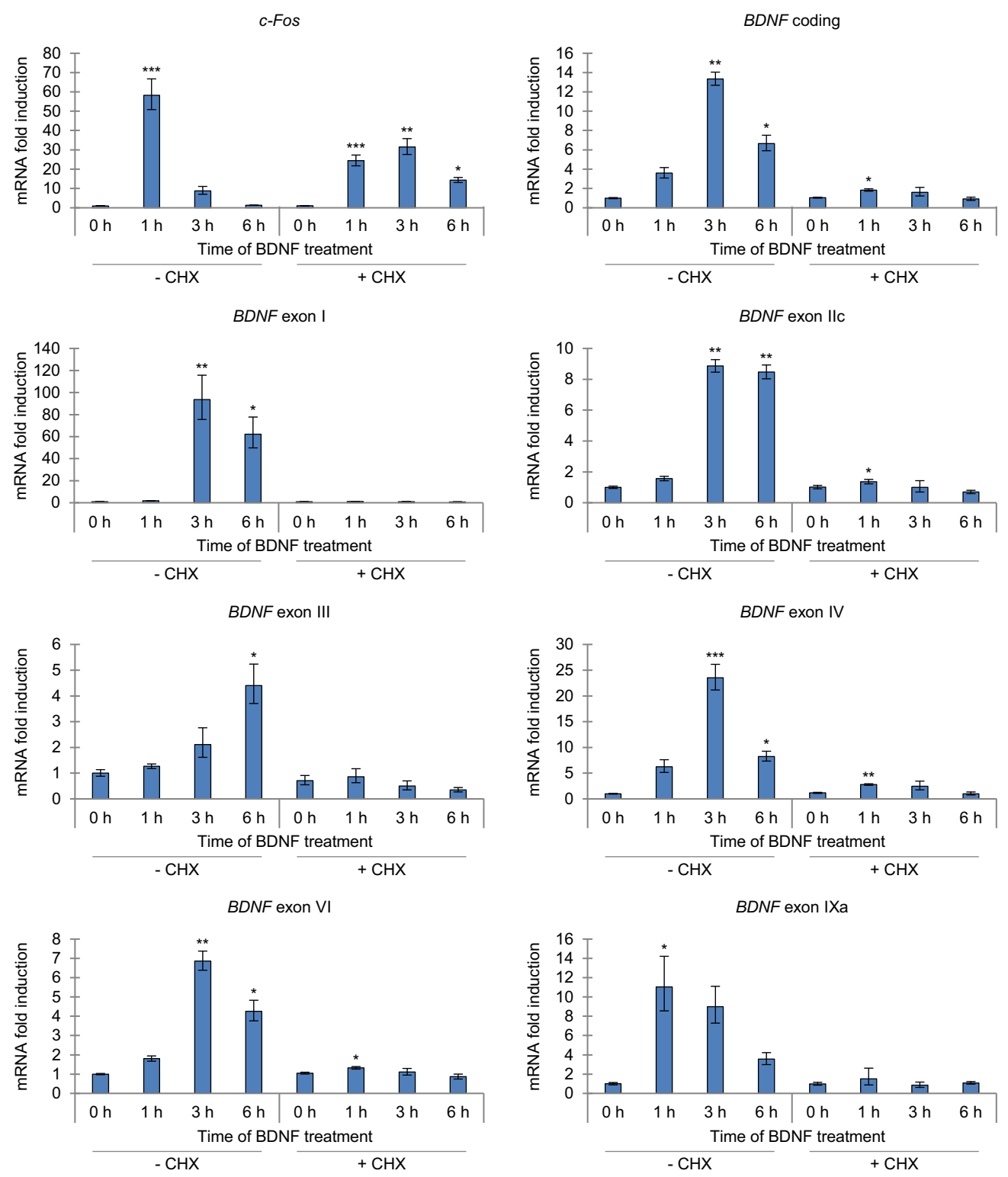

Figure 1. BDNF transcriptional autoregulation requires protein synthesis. At $7 \mathrm{DIV}$, rat primary cortical neurons were treated with $20 \mu \mathrm{g} / \mathrm{ml} \mathrm{CHX} \mathrm{for} 30$ min where indicated and subsequently with $50 \mathrm{ng} / \mathrm{ml} \mathrm{BDNF}$ for the indicated time periods. qRT-PCR was used to measure the levels of $c$-Fos, total BDNF (BDNF coding), and BDNF transcripts. The mRNA fold induction was calculated relative to the respective mRNA level in cells not treated with BDNF and either not treated or treated with CHX, respectively. Average of three independent experiments $(n=3)$ is shown. Error bars indicate SEM. Statistical significance relative to the respective transcript levels in cells not treated with BDNF: ${ }^{* * *} p<0.001 ;{ }^{* *} p<0.01 ;{ }^{*} p<0.05$ (paired two-tailed $t$ test, corrected for multiple comparisons using Holm-Sidak method).

sary for the early induction of BDNF exon IIc-, IV-, and VIcontaining transcripts after BDNF-TrkB signaling are already present in the cell, while the transcription factors that participate in later induction after BDNF-TrkB signaling or regulate other $B D N F$ transcripts are mostly synthesized in response to BDNFTrkB signaling.

\section{CREB family of transcription factors is the main mediator of the early phase of BDNF transcriptional autoregulation}

To investigate which transcription factors, in addition to AP-1, are involved in BDNF transcriptional autoregulation in cultured rat cortical neurons, we used dominant-negative forms of several transcription factor families to impair their potential regulatory role. We focused on transcription factors that have been shown to be involved in BDNF transcriptional regulation in other signaling pathways, particularly on those that are present in the neurons before TrkB signaling and are activated independent of translation. We created AAV vectors encoding the dominant-negative forms of CREB, C/EBP $\alpha$ and $\beta, \mathrm{ATF} 2$, USF, and NFAT families. The dominant-negative proteins A-CREB, A-C/EBP $\alpha, \mathrm{A}-\mathrm{C} /$ $\operatorname{EBP} \beta, A-A T F 2$, and A-USF mediate their dominant-negative effect through dimerization with the respective endogenous transcription factors, thus preventing the transcription factor from binding to DNA and mediating transcriptional regulation (Krylov et al., 1995; Ahn et al., 1998; Qyang et al., 1999). To interfere with NFAT-regulated gene expression, we used overexpression of the VIVIT protein sequence (MAGPHPVIVITGPHEE) that blocks NFAT dephosphorylation by calcineurin and thus prevents NFAT translocation to the nucleus (Aramburu et al., 1999). We verified the expression of the dominant-negative proteins using immunocytochemistry and Western blot analysis (data not shown). Next, we infected neurons with the mentioned 

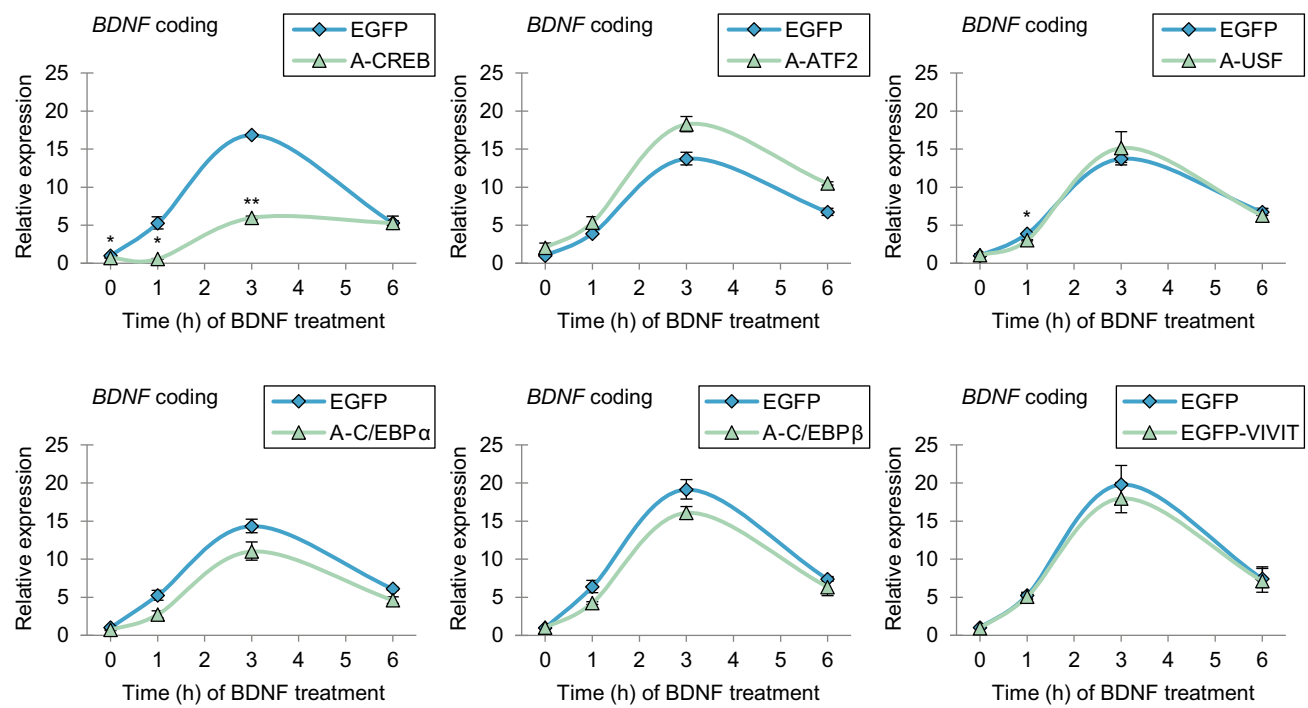

Figure 2. CREB family transcription factors are the main regulators of BDNF transcriptional autoregulation. Primary neurons were transduced at 2 DIV with AAV particles coding for indicated dominant-negative transcription factors or EGFP. At 8 DIV, neurons were treated with $50 \mathrm{ng} / \mathrm{ml} \mathrm{BDNF}$ for the indicated time periods, and the expression levels of total BDNFmRNA (BDNF coding) were measured using qRT-PCR. The expression level of respective transcripts in cells transduced with EGFP-encoding AAV particles and not treated with BDNF was set as 1 . Average of three independent experiments $(n=3)$ is shown. Error bars indicate SEM. Statistical significance between the respective transcript levels in EGFP and respective dominant-negative-overexpressing cells at respective time points: ${ }^{* *} p<0.01 ;{ }^{*} p<0.05$ (paired two-tailed $t$ test, corrected for multiple comparisons using Holm-Sidak method).

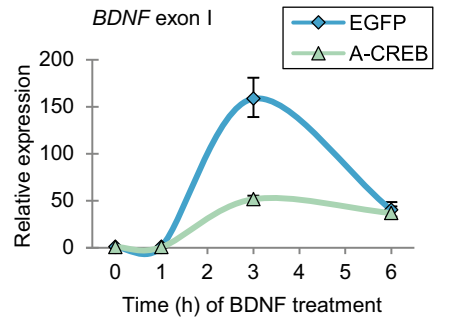

$B D N F$ exon IV

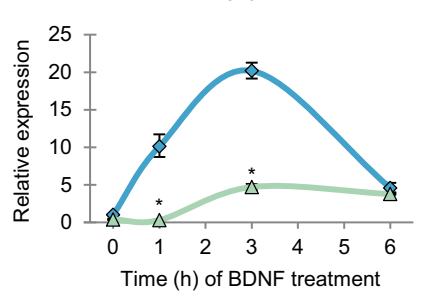

BDNF exon IIc

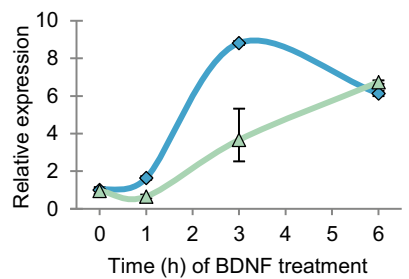

BDNF exon VI

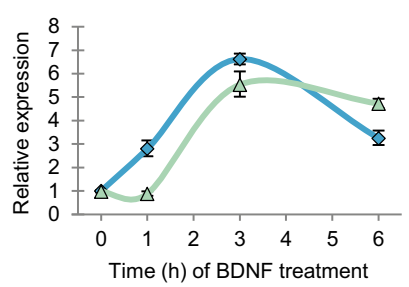

BDNF exon III

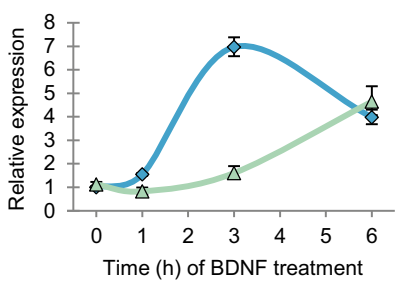

BDNF exon IXa

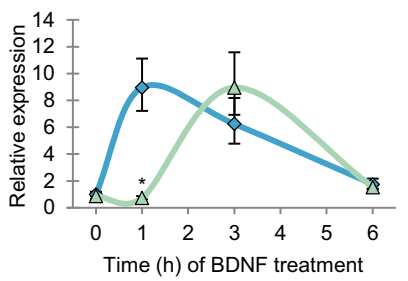

Figure 3. CREB family transcription factors are required for the early induction of all BDNF transcripts in response to BDNF-TrkB signaling. Primary neurons were transduced at 2 DIV with AAV particles coding for EGFP or A-CREB, a dominant-negative form of CREB family transcription factors. At 8 DIV, neurons were treated with $50 \mathrm{ng} / \mathrm{ml}$ BDNF for the indicated time periods; and the expression levels of different BDNF transcripts, as indicated above each graph, were measured using qRT-PCR. The expression level of respective transcripts in cells transduced with EGFP-encoding AAV particles and not treated with BDNF was set as 1 . Average of three independent experiments $(n=3)$ is shown. Error bars indicate SEM. Statistical significance between the respective transcript levels in EGFP and A-CREB-overexpressing cells at respective time points: ${ }^{*} p<0.05$ (paired two-tailed $t$ test, corrected for multiple comparisons using Holm-Sidak method).

AAV vectors at $2 \mathrm{DIV}$, treated the cells with BDNF at $8 \mathrm{DIV}$, and measured the expression levels of BDNF using qRT-PCR (Fig. 2).

The strongest effect on BDNF transcriptional autoregulation was seen in cells overexpressing A-CREB, where the basal expression level of total BDNF mRNA was reduced to 0.69 -fold ( $p=$ 0.0266 ) compared with $B D N F$ expression levels in neurons overexpressing EGFP. In BDNF-treated cells, the overexpression of A-CREB decreased the induced levels of total BDNF mRNA from 5.2 -fold to 0.56 -fold ( $p=0.0252$ ) after $1 \mathrm{~h}$ of BDNF treatment and from 16.8 -fold to 6.0 -fold $(p=0.0054)$ after $3 \mathrm{~h}$ of BDNF treatment. No significant difference between the induced levels of $B D N F$ in EGFP and A-CREB-overexpressing cells was seen at $6 \mathrm{~h}$ of BDNF treatment.
Notably, we did not observe a noteworthy effect of overexpressing A-ATF2, A-USF, A-C/EBP $\alpha$, A-C/EBP $\beta$, or EGFP-VIVIT on the basal levels of BDNF mRNA or on TrkB signaling-induced BDNF levels, indicating that ATF2, USF, C/EBP, and NFAT family transcription factors do not significantly contribute to the BDNF autoregulatory loop in cortical neurons.

As A-CREB had the most prominent effect on BDNF autoregulation, we next investigated the effect of overexpressing A-CREB on the levels of different BDNF transcripts (Fig. 3). The induced levels of exon I-containing $B D N F$ transcripts showed a remarkable decrease from 159 -fold to 52 -fold ( $p=0.1082$, uncorrected $p=0.0282)$ at $3 \mathrm{~h}$ of BDNF treatment. A similar effect was seen for exon IIc- and III-containing BDNF transcripts at $3 \mathrm{~h}$ of BDNF 
A

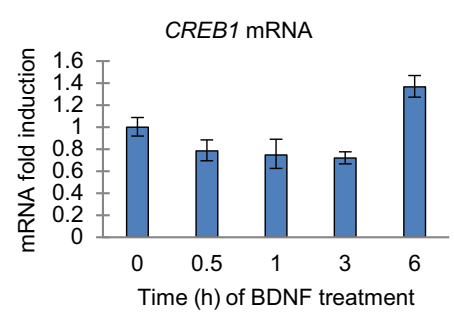

C

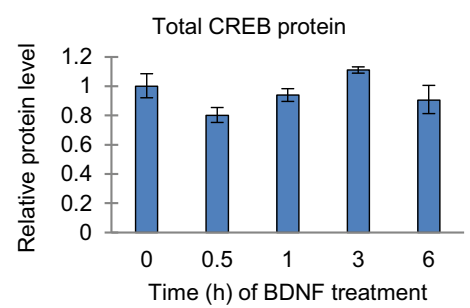

B

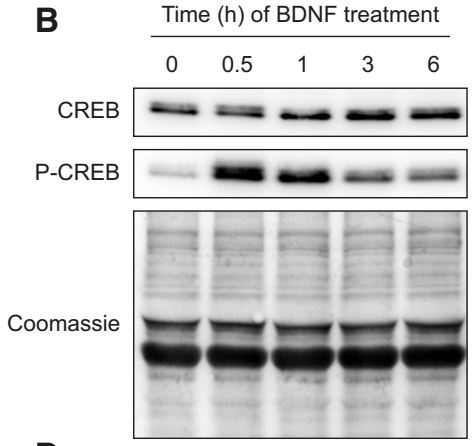

D

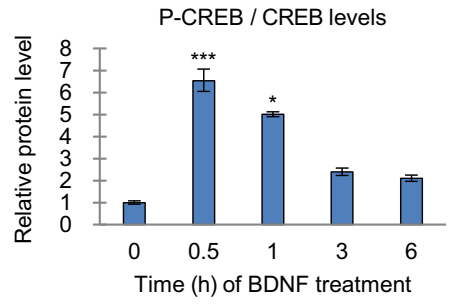

Figure 4. BDNF-TrkB signaling induces CREB phosphorylation but does not influence total CREB protein levels. Primary neurons were treated at 7 DIV with $50 \mathrm{ng} / \mathrm{ml} \mathrm{BDNF}$ for the indicated time periods. $A$, CREB1 mRNA levels, measured using qRT-PCR, are represented as fold induction relative to CREB1 mRNA levels in untreated cells. $\boldsymbol{B}$, Western blot analysis determining CREB and phospho-Ser-133 CREB (P-CREB) protein levels and Coomassie staining for loading control. C, Quantification of total CREB protein levels. CREB protein levels were normalized using Coomassie staining, and normalized CREB protein level in nontreated cells was set as 1.D, Quantification of CREB phosphorylation levels. P-CREB protein levels were normalized to total CREB protein levels, and the relative level of $\mathrm{P}$-CREB protein in nontreated cells was set as $1 . \boldsymbol{A}, \boldsymbol{C}, \boldsymbol{D}$, Average of three independent experiments $(n=3)$ is shown. Error bars indicate SEM. Statistical significance relative to respective mRNA $(\boldsymbol{A})$ or protein $(\boldsymbol{C}, \boldsymbol{D})$ levels in untreated cells: ${ }^{* * *} p<0.001 ;{ }^{*} p<0.05$ (paired two-tailed $t$ test, corrected for multiple comparisons using Holm-Sidak method).

treatment, when the induced levels of these transcripts decreased from 8.8 -fold to 3.7 -fold $(p=0.2775$, uncorrected $p=0.15002$ ) and from 7.0 -fold to 1.6 -fold $(p=0.0776$, uncorrected $p=$ $0.0200)$, respectively.

Overexpression of A-CREB decreased the basal levels of only $B D N F$ exon IV-containing transcripts to 0.4 -fold $(p=0.0575$, uncorrected $p=0.0292$ ) compared with the respective levels in neurons expressing EGFP. Remarkably, A-CREB also completely abolished the induction of exon IV-containing transcripts at $1 \mathrm{~h}$ ( $p=0.0119)$ of BDNF-TrkB signaling and lowered the induced levels at $3 \mathrm{~h}$ from 20 -fold to 4.7 -fold $(p=0.0119)$. A similar tendency was observed for BDNF exon VI- and IXa-containing transcripts, where A-CREB abolished the induction completely at $1 \mathrm{~h}$ time point $(p=0.1078$, uncorrected $p=0.0281$, and $p=$ 0.0343 , respectively). However, at $6 \mathrm{~h}$ of BDNF treatment, the induced levels of all $B D N F$ transcripts were mostly the same in A-CREB and EGFP-overexpressing cells, indicating that other transcription factors outside the CREB family mediate the late induction of $B D N F$ expression in response to TrkB signaling.

As the human Synapsin I promoter used in our AAV vectors is slightly ( $\sim 2$-fold) upregulated in response to BDNF-TrkB signaling (data not shown), we verified the results of A-CREB overexpression using lentiviral vectors expressing EGFP or A-CREB under the control of human $P G K$ promoter, which provides very stable expression in response to BDNF treatment (data not shown). The results obtained using lentivirus-mediated overexpression ( $n=3$, data not shown) were remarkably similar to those obtained with AAV vectors, further strengthening the notion that CREB family transcription factors are the main mediators of the early, but not late, induction of all BDNF transcripts upon TrkB signaling.
CREB is rapidly phosphorylated in response to $B D N F-T r k B$ signaling To confirm BDNF signaling-dependent activation of CREB, as it has been described previously (Finkbeiner et al., 1997; Pizzorusso et al., 2000), in our primary cultures of neurons, we treated neurons with BDNF for different time periods and measured changes in the expression levels of CREB1 mRNA using qRT-PCR and determined CREB and phospho-Ser133 CREB protein levels using Western blot (Fig. 4).

BDNF treatment did not affect CREB1 mRNA expression level (Fig. 4A). Although a small downregulation of $C R E B 1$ mRNA level in response to BDNF-TrkB signaling was consistently observed after 3 $h$ of BDNF treatment, the minor changes in CREB1 mRNA levels were not reflected in CREB protein levels, which remained stable (Fig. $4 B, C$ ). In contrast, BDNFTrkB signaling induced very rapid CREB phosphorylation at Ser-133 (Fig. 4B,D), as expected, considering that post-translational regulation of CREB is well established (for review, see Johannessen et al., 2004). P-CREB levels were $\sim 6.5$-fold $(p=0.00004)$ higher after $0.5 \mathrm{~h}, \sim 5.0$ fold $(p=0.0105)$ higher after $1 \mathrm{~h}$, and stayed $\sim 2$-fold higher after 3 and $6 \mathrm{~h}$ of BDNF treatment compared with P-CREB levels in untreated cells. Together, our results indicate that the activity of CREB after BDNF-TrkB signaling in our neuronal cultures is largely regulated through post-translational means and not by overall change in CREB protein levels.

\section{CREB coactivator $\mathrm{CBP} / \mathrm{p} 300$ is necessary for the $\mathrm{BDNF}$ transcriptional autoregulation}

As the overexpression of A-CREB mostly decreased the early induction, largely corresponding to the period where CREB is phosphorylated, but not the late induction of different $B D N F$ transcripts in response to BDNF-TrkB signaling, we next investigated whether CREB coactivator CBP, which interacts with Ser133 phosphorylated CREB, is involved in regulating the expression of $B D N F$ transcripts after BDNF-TrkB signaling. For that, we used CBP-CREB interaction inhibitor (CCII), which binds to CBP's KIX domain (Best et al., 2004; B. X. Li and Xiao, 2009) and therefore prevents CBP interaction with CREB family members. As p300, a paralogue of CBP, has a highly similar KIX domain, CCII also inhibits CREB-p300 interaction (Breen and Mapp, 2018). We treated cultured rat neurons with CCII before treating the cells with BDNF for different time periods and then measured the levels of $B D N F$ transcripts using qRT-PCR (Fig. 5).

First, we observed no remarkable effect of CCII on the expression of $c$-Fos mRNA in response to BDNF-TrkB signaling (Fig. 5). On the contrary, disturbing $\mathrm{CBP} / \mathrm{p} 300$ recruitment decreased BDNF transcriptional autoregulation and affected the induced levels of most of the BDNF transcripts, whereas the basal expression levels of $B D N F$ transcripts did not change. The induced levels of total BDNF mRNA were reduced from $\sim 3.0$-fold to $\sim 2.0$-fold ( $p=0.2236$, uncorrected $p=0.0809)$ after $1 \mathrm{~h}$, and from $\sim 16$-fold to $\sim 8.0$-fold ( $p=0.0056$ ) after $3 \mathrm{~h}$ of BDNF 


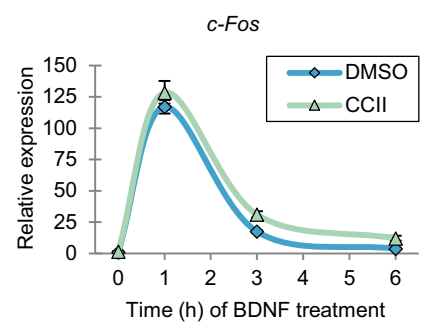

BDNF exon IIc

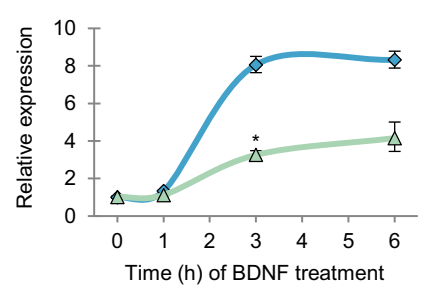

BDNF exon VI

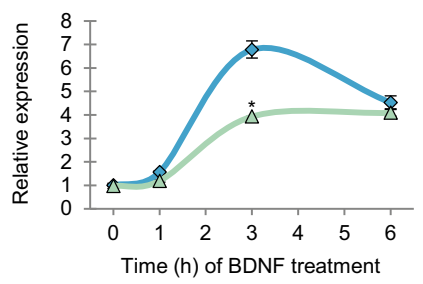

BDNF coding

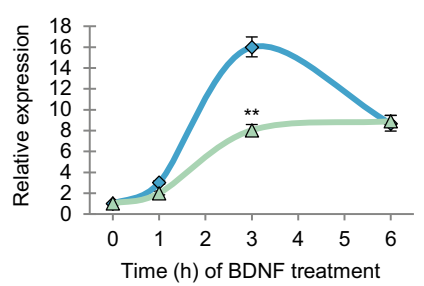

$B D N F$ exon III

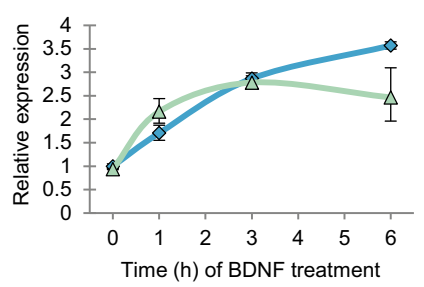

BDNF exon IXa

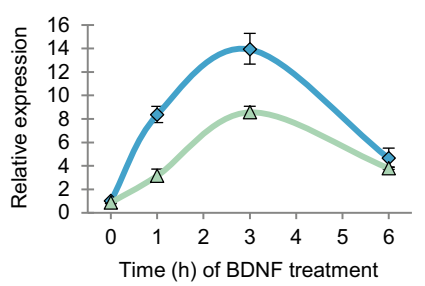

BDNF exon I

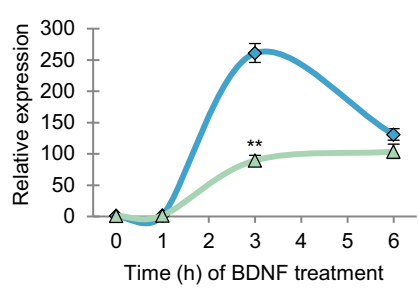

$B D N F$ exon IV

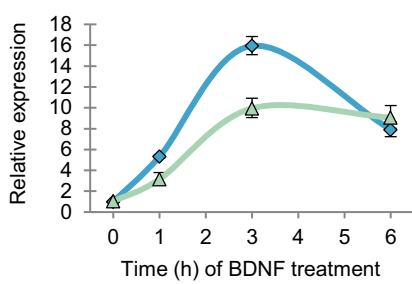

Figure 5. Early, but not late, phase of BDNF transcriptional autoregulation requires CREB-CBP/p300 interaction. At 8 DIV, primary neurons were treated with $5 \mu M$ CBP-CREB interaction inhibitor (CCII) or with DMSO as a control for $1 \mathrm{~h}$ before treating the cells with $50 \mathrm{ng} / \mathrm{ml}$ BDNF for the indicated time periods. qRT-PCR was used to measure $c-F 0$, total BDNF (BDNF coding), and BDNF transcript levels. The expression level of respective transcripts in vehicle-treated cells not treated with BDNF was set as 1 . Average of three independent experiments ( $n=3$ ) is shown. Error bars indicate SEM. Statistical significance between respective transcript levels in DMSO and CCIl-treated cells at respective time points: ${ }^{* *} p<0.01$; ${ }^{*} p<0.05$ (paired two-tailed $t$ test, corrected for multiple comparisons using Holm-Sidak method).

treatment in CCII-treated cells. In cells pretreated with CCII, the induced levels of BDNF transcripts containing exon IV and IXa were decreased from $\sim 5.3$-fold to $\sim 3.2$-fold $(p=0.2972)$ and from $\sim 8.4$-fold to $\sim 3.1$-fold ( $p=0.1486$ ), respectively, after $1 \mathrm{~h}$ of BDNF treatment, and from $\sim 16$-fold to $\sim 9$.9-fold ( $p=$ 0.0647 ) and from $\sim 14$-fold to $\sim 8.6$-fold ( $p=0.1707$ ), respectively, after $3 \mathrm{~h}$ of BDNF treatment. The induced levels of BDNF transcripts containing exon I, IIc, and VI were decreased by $\sim 2$ fold ( $p=0.0072, p=0.0402$, and $p=0.0359$, respectively) in cells pretreated with CCII after $3 \mathrm{~h}$ of BDNF treatment. The expression levels of BDNF exon III-containing transcripts did not depend on $\mathrm{CBP} / \mathrm{p} 300$ recruitment. Interestingly, after $6 \mathrm{~h}$ of BDNF treatment, there were no differences in the induced levels of most BDNF transcripts, except for exon IIc-containing transcripts, in cells treated with DMSO or CCII, indicating that CREB-CBP/p300 interaction is largely dispensable for the later phases of BDNF transcriptional autoregulation.

To further elucidate the role of CBP/p300 in BDNF gene regulation, we overexpressed adenoviral E1A gene, which encodes proteins that are known to function as dominant-negative for $\mathrm{CBP} / \mathrm{p} 300$ and impair CBP/p300-regulated transcription (Kalvakolanu et al., 1992; Lundblad et al., 1995; Nakajima et al., 1997). First, we noted a (Fig. 6) statistically insignificant $\sim 3.3$-fold increase $(p=0.2957$, uncorrected $p=0.1227)$ in the basal expression level of $c$-Fos, and $\sim 2$-fold decrease $(p=0.1963$, uncorrected $p=0.0532$ ) in the induced levels of $c$-Fos mRNA after $1 \mathrm{~h}$ of BDNF treatment (Fig. 6). Notably, we also observed that the basal expression of most BDNF transcripts, except for transcripts containing BDNF exon VI, was upregulated 1.3-fold to 1.8 -fold, and even 4.7-fold ( $p=0.1603$, uncorrected $p=$ 0.0786 ) for exon I-containing BDNF transcripts, by E1A overexpression (Fig. 6). In contrast, the basal levels of exon VIcontaining BDNF transcripts was decreased $\sim 2$-fold $(p=$ 0.1980 , uncorrected $p=0.1494$ ) in E1A-expressing cells. The TrkB signaling-induced levels of total BDNF mRNA were reduced from $\sim 4$.4-fold to $\sim 1.7$ fold ( $p=0.0456$ ) after $1 \mathrm{~h}$, from $\sim 9$-fold to $\sim 2.6$-fold ( $p=0.0458$ ) after $3 \mathrm{~h}$, and from $\sim 4.2$-fold to $\sim 2$-fold ( $p=0.0458$ ) after $6 \mathrm{~h}$ of BDNF treatment. Correspondingly, the induced levels of all BDNF transcripts after BDNF-TrkB signaling were diminished after E1A overexpression. Notably, the induced levels of BDNF transcripts containing exon IV were reduced from $\sim 6.9$-fold to 2.1 -fold ( $p=0.0064$ ) after $1 \mathrm{~h}$, from 8.0 -fold to 1.8 -fold $(p=0.0064)$ after $3 \mathrm{~h}$, and from 2.8 -fold to 1.2 -fold ( $p=0.0843$, uncorrected $p=0.0431$ ) after $6 \mathrm{~h}$ of BDNF treatment by E1A overexpression. Together, our results show that $\mathrm{CBP} / \mathrm{p} 300$ is absolutely required for the regulation of $B D N F$ transcription in response to $B D N F-T r k B$ signaling.

\section{CREB coactivator CRTC does not participate in BDNF transcriptional autoregulation}

Next, to further elucidate the mechanism of CREB familyregulated $B D N F$ gene expression, we investigated whether other CREB coactivators are required for the BDNF transcriptional autoregulation. Three CRTCs have been described, but CRTC1 is the most abundantly expressed member of the CRTC family in the CNS (Watts et al., 2011; Saura and Cardinaux, 2017). It has also been shown that CRTC1 KO mice have lower levels of differ- 
c-Fos

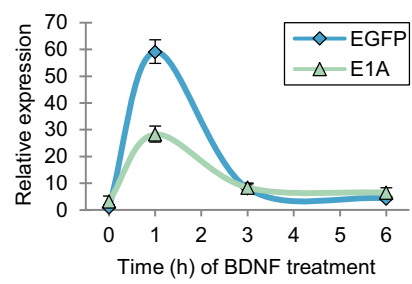

$B D N F$ exon Ilc

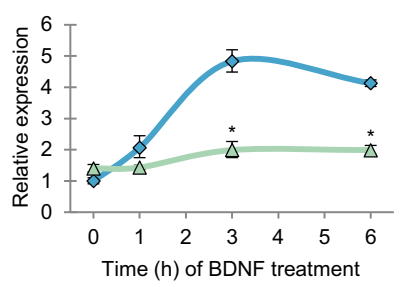

BDNF exon VI

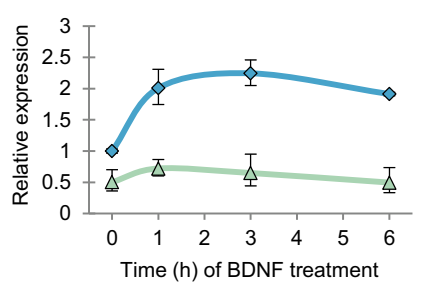

$B D N F$ coding

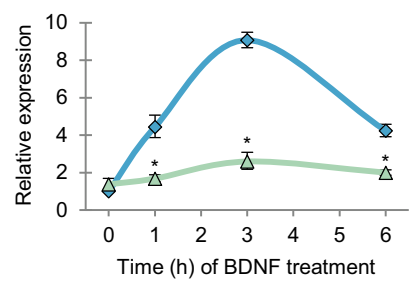

BDNF exon III

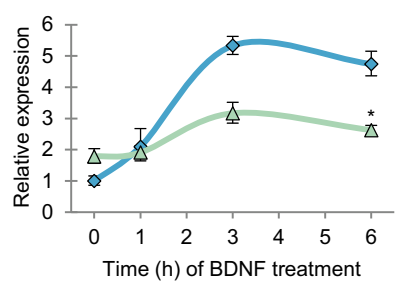

BDNF exon IXa

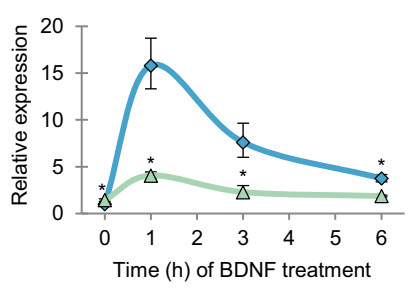

BDNF exon I

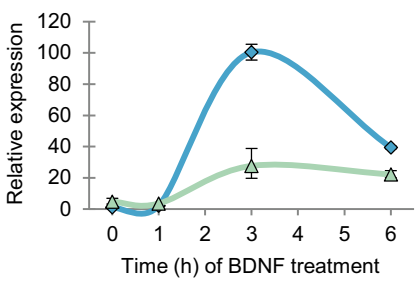

BDNF exon IV

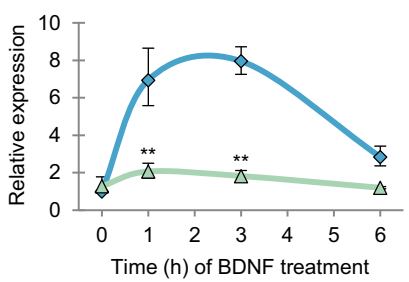

Figure 6. Activity of CBP/p300 is necessary for both the early and late induction of all BDNF transcripts after BDNF-TrkB signaling. Primary neurons were transduced at 5 DIV with lentiviral particles encoding EGFP, as control, or E1A, a dominant-negative for CBP/p300. At 8 DIV, neurons were treated with $50 \mathrm{ng} / \mathrm{ml}$ BDNF for the time indicated. qRT-PCR was used to measure c-Fos, total BDNF (BDNF coding), and BDNF transcript levels. The expression level of respective transcripts in cells expressing EGFP not treated with BDNF was set as 1 . Average of three independent experiments ( $n=$ 3) is shown. Error bars indicate SEM. Statistical significance between respective transcript levels in EGFP and E1A-expressing cells at respective time points: ${ }^{* *} p<0.01$; ${ }^{*} p<0.05$ (paired two-tailed $t$ test, corrected for multiple comparisons using Holm-Sidak method).

ent BDNF transcripts both in PFC and in hippocampus (Breuillaud et al., 2012), suggesting a possible role for CRTC1 in BDNF gene regulation. Therefore, we first chose to investigate whether CRTC1 localizes to the nucleus in response to BDNF-TrkB signaling, as it has been established for various treatments (e.g., forskolin, membrane depolarization with $\mathrm{KCl}$ and NMDA) (Bittinger et al., 2004; Zhou et al., 2006; S. Li et al., 2009; Ch'ng et al., 2012; Fukuchi et al., 2014, 2015; Uchida et al., 2017). We analyzed CRTC1 localization in untreated neurons and neurons treated with BDNF using immunocytochemistry. We used $\mathrm{KCl}$ treatment as a positive control. Our results show that, in unstimulated cortical neurons, CRTC1 is mainly localized in the cytoplasm, whereas after $1 \mathrm{~h} \mathrm{KCl}$ treatment almost all of CRTC1 is localized to the nucleus (Fig. 7). After BDNF treatment, the nuclear localization of CRTC1 increases in the majority of the cells; however, a detectable amount of CRTC1 also remains in the cytoplasm. Similar results were also observed after 3 and $6 \mathrm{~h}$ treatments (data not shown). Together, our data show that CRTC1 is translocated to the nucleus after BDNF treatment, although with lower efficiency than after membrane depolarization, and could possibly be involved in BDNF autoregulation.

Next, to investigate whether CRTC1 regulates BDNF gene expression after BDNF-TrkB signaling, we suppressed CRTC1 gene expression using CRISPR interference with lentivirus-mediated overexpression of dCas 9 protein coupled with KRAB repressor domain, and two gRNAs targeted to CRTC1 promoter region. We transduced cultured rat neurons with lentiviral particles at 0 DIV, treated neurons with BDNF at 8 DIV, and used luciferase reporter assay to estimate CRE-reporter activity or qRT-PCR to
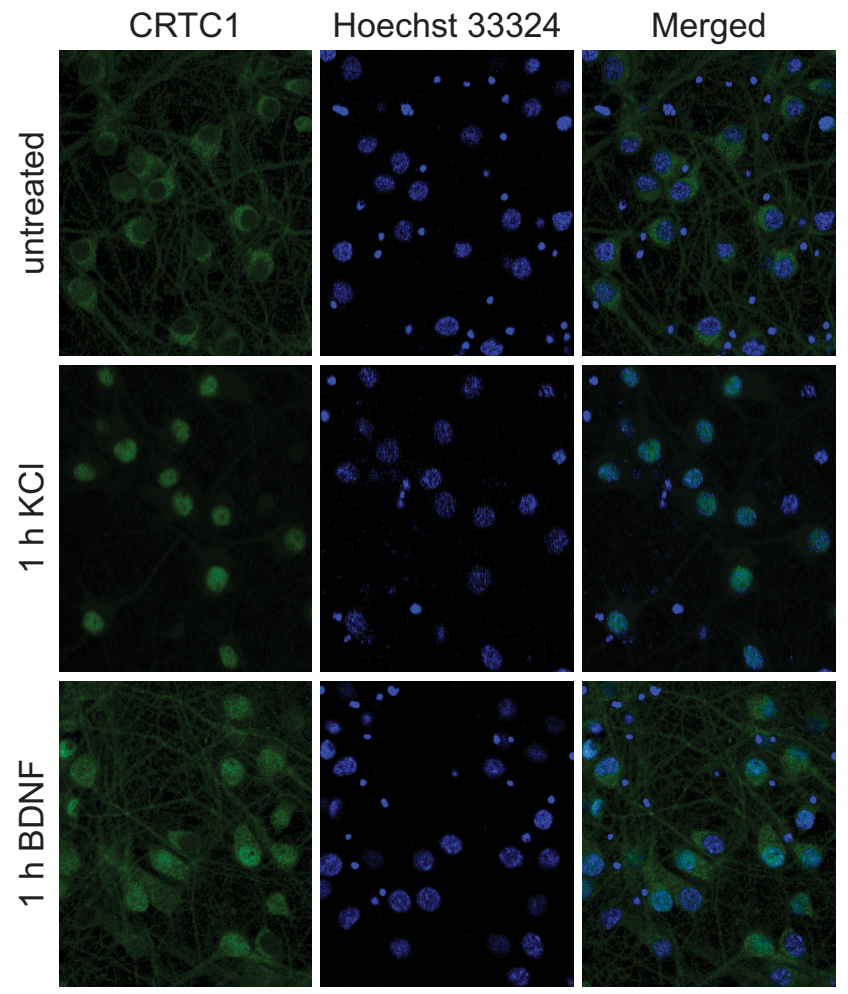

Figure 7. CRTC1 localizes to the nucleus after BDNF treatment. At 8 DIV, neurons were treated with $25 \mathrm{~mm} \mathrm{KCl}$, as a positive control, or $50 \mathrm{ng} / \mathrm{ml} \mathrm{BDNF}$. Immunocytochemistry was performed using anti-CRTC1 antibody (green). Hoechst 33324 was used to visualize nuclei (blue). 

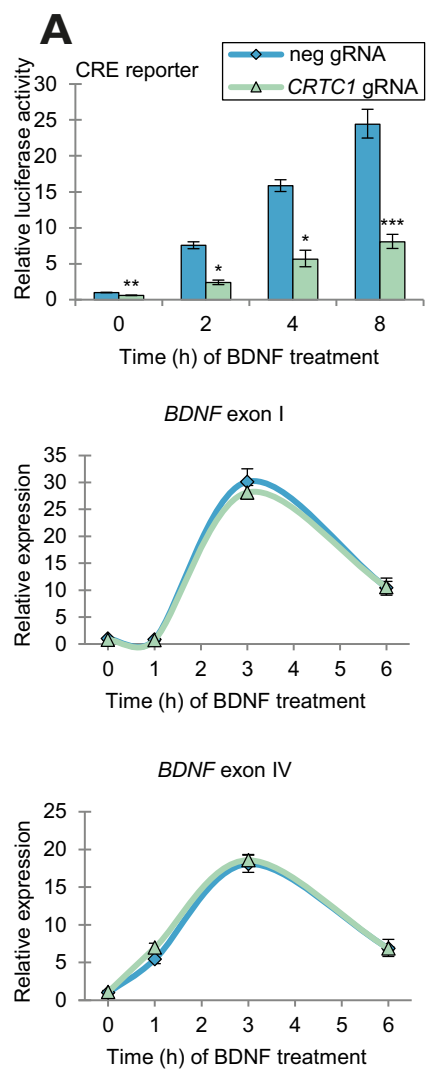

B

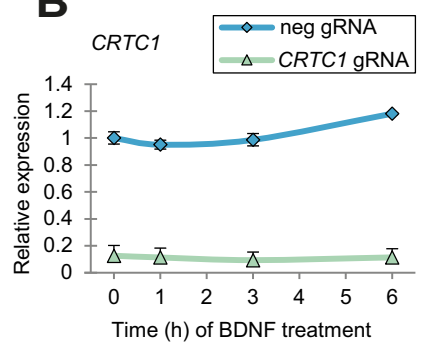

$B D N F$ exon Ilc

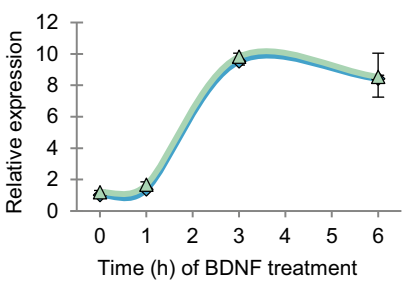

$B D N F$ exon $\mathrm{VI}$

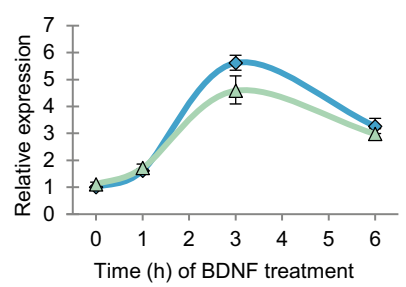

BDNF coding

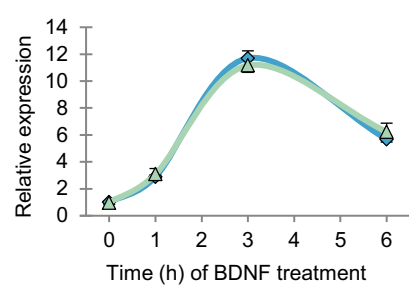

BDNF exon III

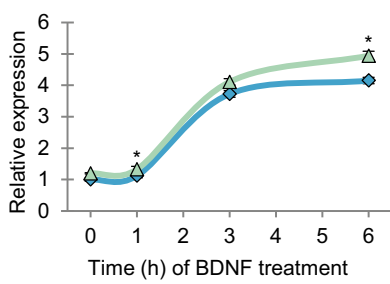

$B D N F$ exon IXa

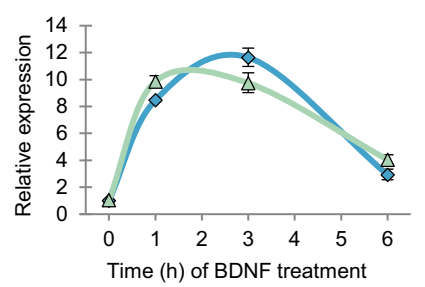

Figure 8. CREB coactivator CRTC1 does not participate in the induction of BDNF gene expression after BDNF-TrkB signaling. Primary neurons were transduced at 0 DIV with lentiviral particles coding for dCas9-KRAB, and a combination of two CRTC1 gRNAs or negative gRNA (neg gRNA). $A$, Transduced neurons were transfected with CRE-reporter at 6 DIV, and luciferase reporter activity was measured at 8 DIV after BDNF treatment $(n=4)$. Luciferase activity in cells transduced with dCas9-KRAB and negative gRNA-encoding lentiviral particles and not treated with BDNF was set as 1. $\boldsymbol{B}$, At 8 DIV, neurons were treated with $50 \mathrm{ng} / \mathrm{ml}$ BDNF for the indicated time periods, and the expression levels of $C R T C 1$, total $B D N F(B D N F$ coding), and different $B D N F$ transcripts were measured using qRT-PCR. The expression level of respective transcripts in cells transduced with dCas9-KRAB and negative gRNA-encoding lentiviral particles and not treated with BDNF was set as 1 . Average of three independent experiments $(n=3)$ is shown. Error bars indicate SEM. Statistical significance between the respective transcript levels in negative gRNA and CRTC1 gRNA-overexpressing cells at respective time points: ${ }^{* * *} p<0.001 ;{ }^{* *} p<0.01 ;{ }^{*} p<0.05$ (paired two-tailed $t$ test, corrected for multiple comparisons using Holm-Sidak method).

measure the expression levels of BDNF transcripts (Fig. 8). Using such CRISPR interference system, we succeeded in repressing CRTC1 mRNA expression $\sim 8$-fold $(p=0.1304$, uncorrected $p=$ 0.0413 ) (Fig. $8 B$ ), which also resulted in $\sim 2$-fold to 3 -fold decrease in the activation of CRE-reporter at different time points after BDNF-TrkB signaling (Fig. 8A). For example, CRTC1 knockdown reduced CRE-reporter activation from 24-fold to 8 -fold ( $p=0.0006)$ at $8 \mathrm{~h} \mathrm{BDNF}$ treatment. However, the reduction of CRTC1 had no remarkable effect on the induction of any $B D N F$ transcript after BDNF-TrkB signaling (Fig. $8 B$ ). Of note, no compensatory increase in the expression of CRTC2 and CRTC3 mRNA was detected in response to repressing the expression of CRTC1 (data not shown).

Finally, we decided to take a wider approach in studying the role of CRTC family of CREB coactivators by overexpressing a dominant-negative protein for CRTC, which consists of the first 44 amino acids of CRTC1 protein. This dominant-negative CRTC binds to CREB and impairs the interaction of CREB with the members of CRTC family (used by Bittinger et al., 2004; Zhou et al., 2006; Kovács et al., 2007; Uchida et al., 2017). As a positive control, we first determined that overexpression of dominantnegative CRTC reduces BDNF-TrkB signaling-induced CREreporter activity $\sim 2$-fold at every measured time point, albeit statistically insignificantly (Fig. 9A). Meanwhile, overexpression of dominant-negative CRTC did not affect the basal expression nor BDNF-TrkB signaling-induced levels of any BDNF transcript
(Fig. 9B). Together, our results show that CREB coactivators from the CRTC family do not participate in BDNF transcriptional autoregulation.

\section{CRE element in rat $B D N F$ promoter IV is required for the activation of the promoter after BDNF-TrkB signaling}

Next, to determine the role of CREB family transcription factors in the activation of BDNF proximal promoter regions after BDNF-TrkB signaling, we used luciferase reporter assay. We transfected cultured rat neurons with rat BDNF ( $\mathrm{r} B D N F)$ promoter I, II, III, IV, VI, and IXa constructs, or CRE reporter as a positive control, together with either EGFP or A-CREB overexpression vectors. In addition, we used a short version of $\mathrm{r} B D N F$ promoter I that contains only the $5^{\prime}$ transcription start site of the promoter I, designated here as $\mathrm{r} B D N F$ promoter I $5^{\prime}$, as it has been shown to be more inducible than the full-length promoter I after membrane depolarization (Pruunsild et al., 2011). Finally, we treated neurons with BDNF and measured promoter activity using luciferase assay (Fig. 10A).

First, we observed that overexpression of A-CREB reduced the basal activity of CRE reporter in unstimulated cells $\sim 3$.4-fold ( $p=0.0022)$, and decreased the BDNF-TrkB signaling-induced activity of the CRE reporter by $\sim 11$-fold $(p=0.0061)$ and by $\sim 15$-fold ( $p=0.0114$ ) after 4 and $8 \mathrm{~h}$ of BDNF treatment, respectively (Fig. 10A), indicating the functionality of our reporter assay. Overexpression of A-CREB had no significant effect on the 

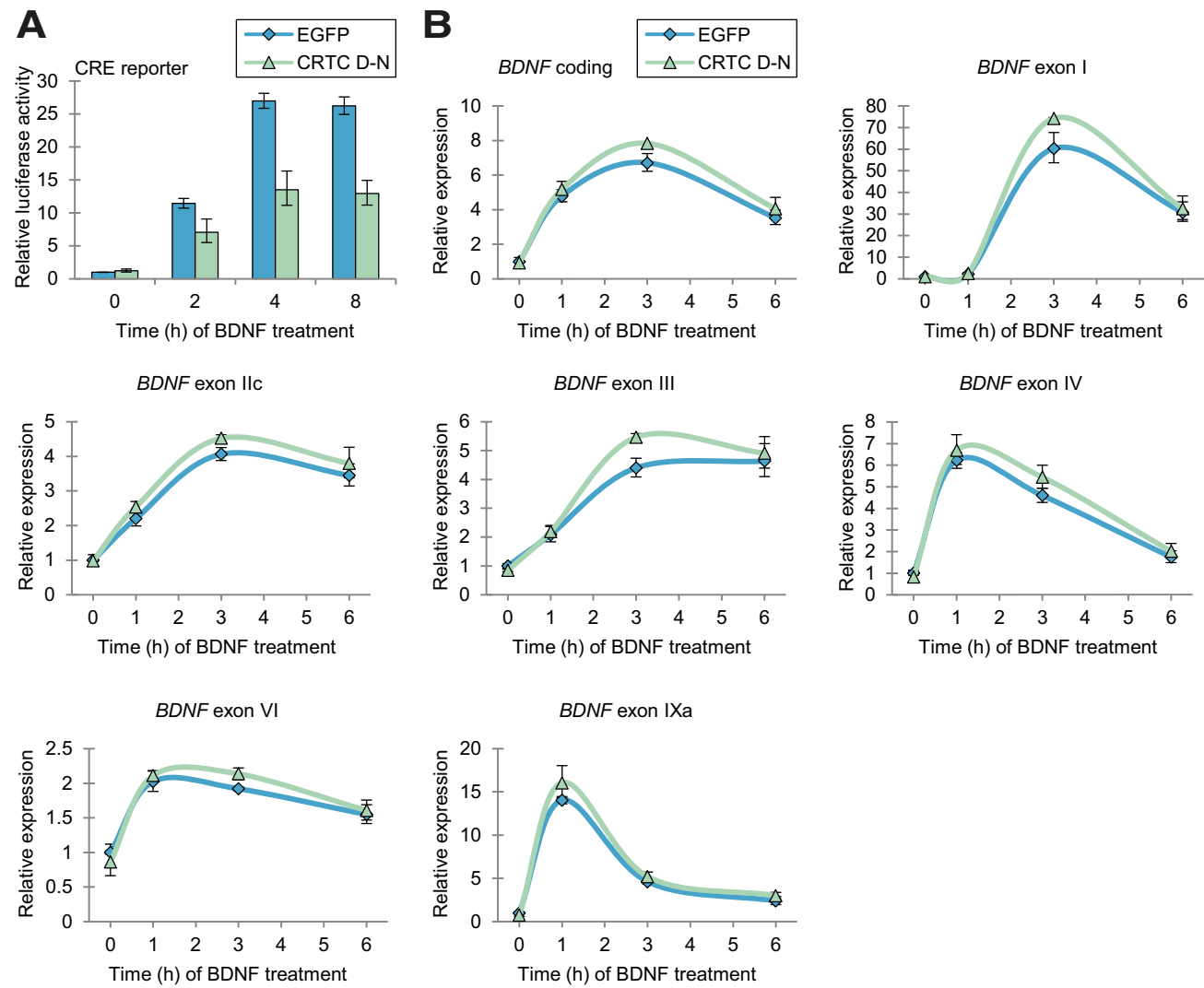

Figure 9. The CRTC family does not participate in the induction of BDNF transcripts after BDNF-TrkB signaling. Primary neurons were transduced at 0 DIV with lentiviral particles encoding EGFP, as control, or CRTC dominant-negative protein (CRTC D-N). $A$, Transduced neurons were transfected with CRE-reporter at 6 DIV, and luciferase reporter activity was measured at 8 DIV after BDNF treatment for the time indicated $(n=4)$. Luciferase activity in cells transduced with EGFP-encoding lentiviral particles and not treated with BDNF was set as $1 . \boldsymbol{B}$, At 8 DIV, transduced neurons were treated with $50 \mathrm{ng} / \mathrm{ml}$ BDNF for the time indicated, and the levels of total BDNF (BDNF coding) and different BDNF transcripts were measured using qRT-PCR. The expression level of respective transcripts in cells expressing EGFP not treated with BDNF was set as 1. Average of 3 independent experiments $(n=3)$ is shown. Statistical significance between respective transcript levels in EGFP and CRTC D-N-expressing cells at respective time points: no statistically significant results (paired two-tailed t test, corrected for multiple comparisons using Holm-Sidak method). Error bars indicate SEM.

basal activity of rBDNF promoters I, I 5', VI, and IXa. Notably, we saw a $\sim 1.5$-fold decrease $(p=0.0366)$ in the basal activity of rBDNF promoter IV in cells overexpressing A-CREB. Interestingly, A-CREB overexpression slightly increased the basal activity of $\mathrm{rBDNF}$ promoters II and III by $\sim 1.3$-fold $(p=0.0304)$ and $\sim 1$.1-fold ( $p=0.0348$ ), respectively.

Next, we determined that overexpression of A-CREB reduced the TrkB signaling-dependent activation of $\mathrm{r} B D N F$ promoters I, I $5^{\prime}$, and IV after $4 \mathrm{~h}$ of BDNF treatment from $\sim 5.2$-fold to $\sim 4.0$ fold ( $p=0.1937$ ), from $\sim 7.4$-fold to $\sim 4$.9-fold ( $p=0.0012$ ), and from $\sim 2.4$-fold to $\sim 1.4$-fold ( $p=0.0829)$, respectively. Similar tendencies were observed after $8 \mathrm{~h}$ of BDNF treatment when overexpression of A-CREB reduced the BDNF-TrkB signalinginduced activity of $\mathrm{r} B D N F$ promoter I from $\sim 6.6$-fold to $\sim 5.1$ fold ( $p=0.2022$, uncorrected $p=0.1068)$, promoter I $5^{\prime}$ from $\sim 12$-fold to $\sim 8$.6-fold ( $p=0.0174$ ), and promoter IV from $\sim 3.0$-fold to $\sim 1.7$-fold ( $p=0.0303$ ). Overexpression of A-CREB enhanced the BDNF-induced activity of rBDNF promoter II and VI from $\sim 2$.6-fold to $\sim 3$.6-fold $(p=0.0033$ ) and from $\sim 1.4$ fold to $\sim 1.7$-fold ( $p=0.0981$, uncorrected $p=0.0473$ ), respectively, after $4 \mathrm{~h}$, and from $\sim 3.0$-fold to $\sim 4$.3-fold ( $p=0.0030$ ) and from $\sim 1$.6-fold to $\sim 2.0$-fold $(p=0.0981$, uncorrected $p=$ 0.0338 ), respectively, after 8 h of BDNF-TrkB signaling. The TrkB signaling-induced activity of $\mathrm{rBDNF}$ promoter III was not changed in response to overexpressing A-CREB. Notably, the activity of $\mathrm{r} B D N F$ promoter IXa was not inducible in response to
BDNF-TrkB signaling, and we could not detect any effect of A-CREB overexpression on the activity of this promoter region.

As it has been described that rat BDNF promoters I and IV have a functional CRE element (Shieh et al., 1998; Tao et al., 1998; Tabuchi et al., 2002), we next investigated the importance of these CRE elements by overexpressing rBDNF promoter constructs where the respective CRE element was mutated (Fig. 10B). Our results showed that mutating the CRE element slightly decreased the induction of rBDNF promoter I from $\sim 7.4$-fold to $\sim 6.1$-fold $(p=0.1845$, uncorrected $p=0.0657$ ) after $4 \mathrm{~h}$, and from $\sim 8.5$-fold to $\sim 7.1$-fold $(p=0.1331$, uncorrected $p=$ 0.0351 ) after $8 \mathrm{~h}$ of BDNF treatment in cells expressing EGFP (Fig. 10B). In cells overexpressing A-CREB, the mutation in CRE element reduced the induction of $\mathrm{r} B D N F$ promoter I from $\sim 5.5$ fold to $\sim 4.9$-fold ( $p=0.3463$, uncorrected $p=0.2550$ ) after $4 \mathrm{~h}$, and from $\sim 6.7$-fold to $\sim 5.4$-fold $(p=0.3463$, uncorrected $p=$ 0.1915 ) after $8 \mathrm{~h}$ of BDNF treatment. A similar effect was observed for $\mathrm{r} B D N F$ promoter I $5^{\prime}$, in which case the mutation in CRE element slightly reduced the induction of the promoter activity. In cells expressing EGFP, rBDNF promoter IV lost all of its induction when CRE element was mutated, as promoter induction decreased from $\sim 2.7$-fold to $\sim 1$.2-fold $(p=0.0317$ ) after $4 \mathrm{~h}$, and from $\sim 3.1$-fold to $\sim 0.84$-fold ( $p=0.0016$ ) after $8 \mathrm{~h}$ of BDNF treatment. Similarly, in cells overexpressing A-CREB, the mutation in CRE site decreased the induction of $\mathrm{rBDNF}$ promoter IV from $\sim 1.8$-fold to $\sim 1$.4-fold ( $p=0.0317$ ) after $4 \mathrm{~h}$, and 
A

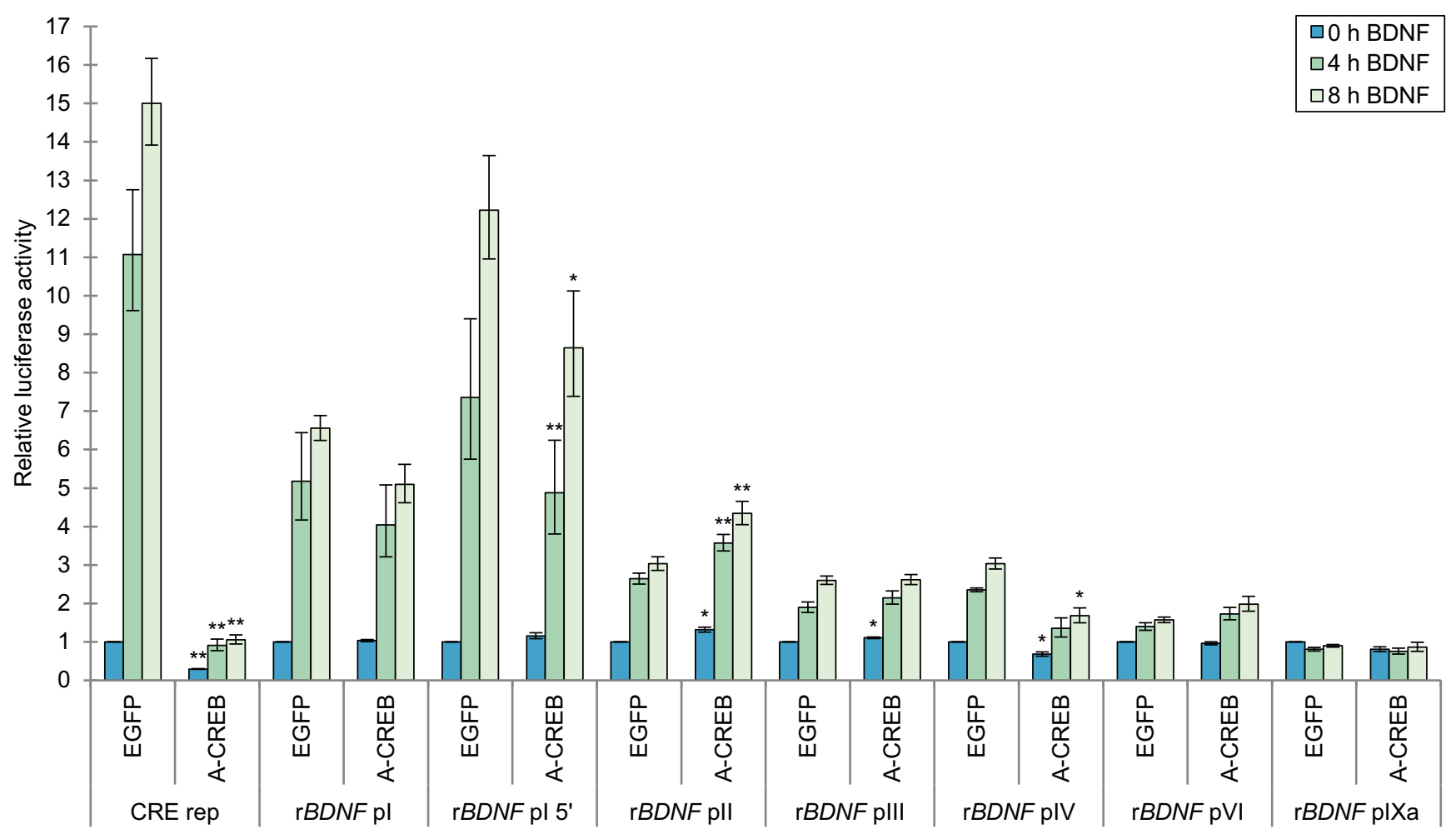

B
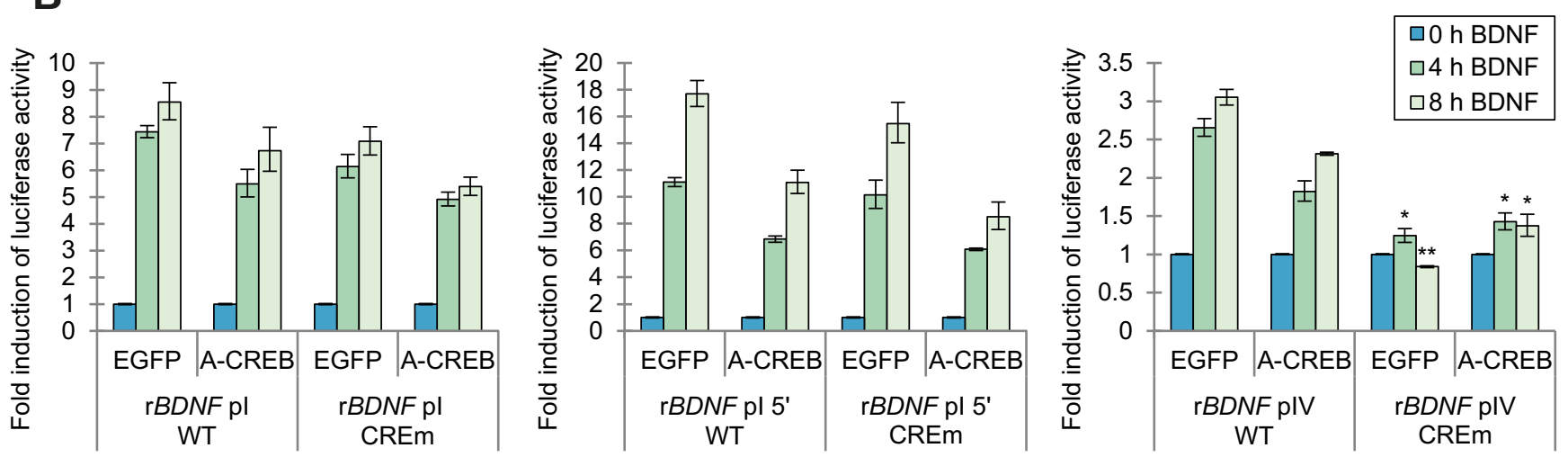

Figure 10. CREB family transcription factors are involved in the activation of rat BDNF promoters I and IV after BDNF-TrkB signaling. Primary neurons were transfected at 6 DIV with different rat BDNF promoter constructs or CRE reporter (CRE rep) together with EGFP or A-CREB overexpression constructs $(\boldsymbol{A})$ or with wild-type (WT) rat $B D N F$ promoter (rBDNF $\mathrm{p}$ ) constructs and respective rat BDNF promoter constructs with mutated CRE site (CREm) together with EGFP or A-CREB overexpression constructs $(B)$ as shown below the graph. At 7 DIV, neurons were treated with $50 \mathrm{ng} / \mathrm{ml}$ BDNF for $4 \mathrm{~h}(n=3)$ or $8 \mathrm{~h}(n=4)(A)$ and for $4 \mathrm{~h}(n=3)$ or $8 \mathrm{~h}(n=3)(B)$ or left untreated, and promoter activity was measured using luciferase reporter assay. Promoter activity was calculated relative to the respective promoter activity in cells transfected with EGFP and not treated with BDNF $(\boldsymbol{A})$ or as fold induction relative to the respective promoter activity in untreated cells transfected with EGFP or A-CREB, respectively $(\boldsymbol{B})$. Average of three or four independent experiments $(n=3$ or 4$)$ is shown. Error bars indicate SEM. Statistical significance between the activity of respective promoter regions in EGFP and A-CREB-overexpressing cells at respective time points $(A)$ or between the induction of respective WT and CREm promoter regions in cells overexpressing EGFP or A-CREB, respectively, at respective time points $(\boldsymbol{B}) .{ }^{* *} p<0.01 ;{ }^{*} p<0.05$ (paired two-tailed $t$ test, corrected for multiple comparisons using Holm-Sidak method).

from $\sim 2.3$-fold to $\sim 1.4$-fold $(p=0.0420)$ after $8 \mathrm{~h}$ of BDNF treatment.

Collectively, our results show that CREB family proteins and the described CRE element in the BDNF promoter I region does not contribute significantly to the activation of the promoter after BDNF-TrkB signaling. In contrast, the induction of $B D N F$ promoter IV activity after BDNF-TrkB signaling is mainly mediated by CREB family transcription factors through the CRE site in the promoter region.
TrkB signaling-dependent regulation of $B D N F$ promoters $I$ and IV, but not promoter IXa, by CREB family proteins is partially conserved between rat and human

Functional CRE elements, which participate in neuronal activitydependent induction of the respective promoter activity, have been described in human BDNF promoters I, IV, and IXa (Pruunsild et al., 2011). We next decided to investigate whether the role of CREB family transcription factors in the induction of $B D N F$ proximal promoter regions in response to BDNF-TrkB 
A

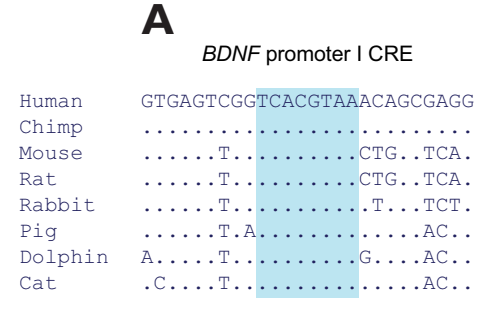

B $B D N F$ promoter IV CRE

ATATGACAGCGCACGTCAAGGCACCG $\ldots \ldots \ldots \ldots \ldots \ldots \ldots \ldots \ldots \ldots \ldots \ldots \ldots \ldots \ldots \ldots \ldots$

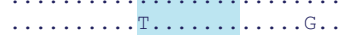
$\ldots \ldots \ldots \ldots$. $\ldots \ldots \ldots \ldots \ldots$.

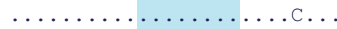
n.m.

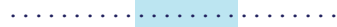
. $\ldots \ldots \ldots \ldots \ldots \ldots \ldots$
C BDNF promoter IXa CRE

GTGTTTCTCGTGACAGCATGAGCAGA

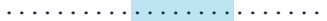
................... ..........G.G...... ..... T.G.T........ .С...СТ...... С..... ..... Ст......СС..... ..... т...... . . .
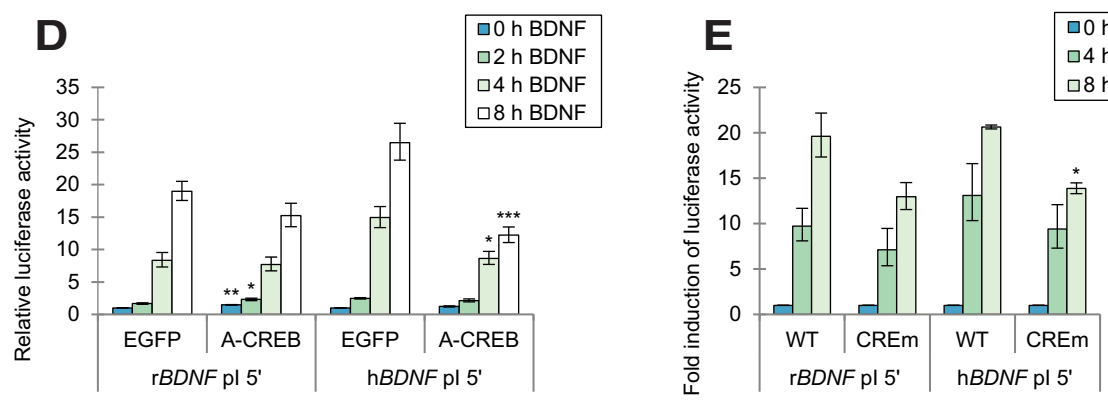

$\mathbf{F}$
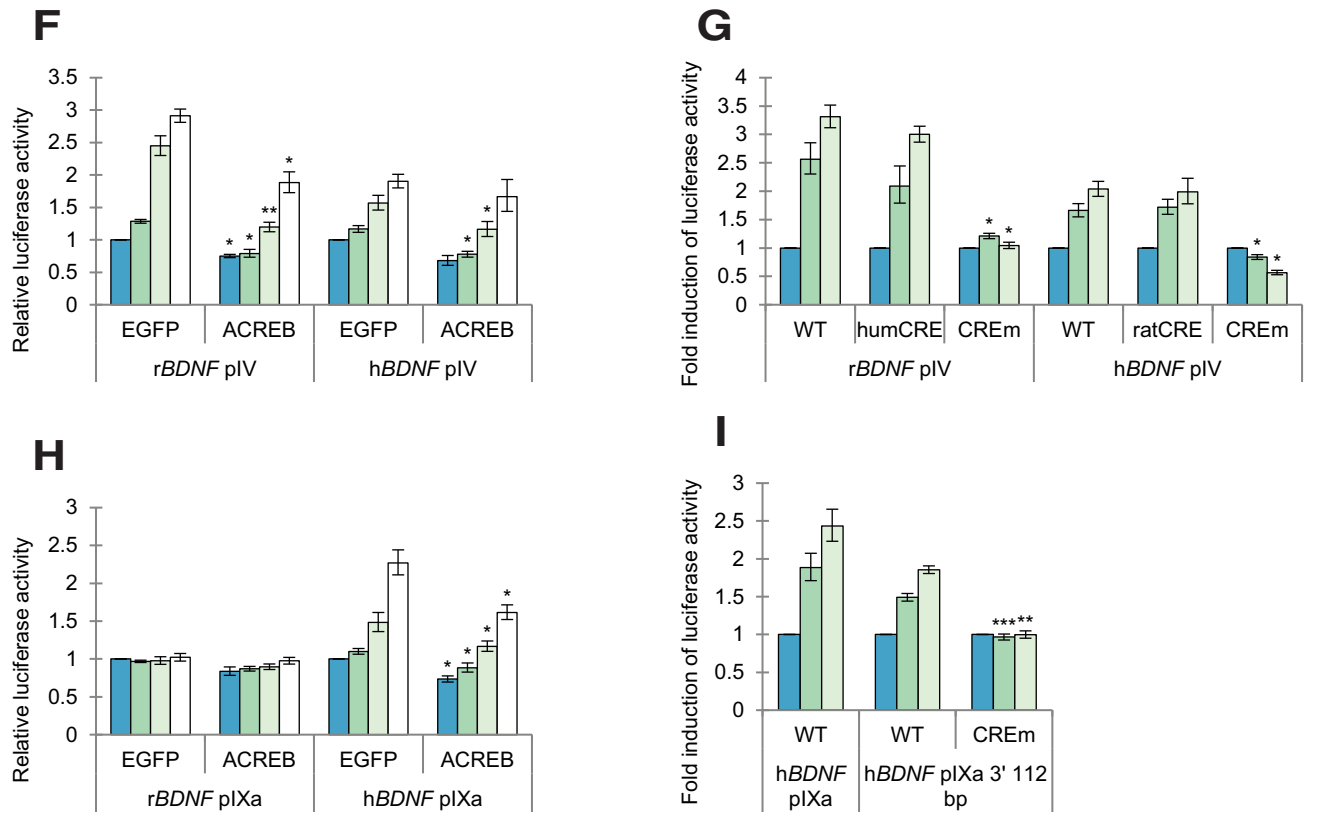

Figure 11. Regulation of BDNF promoters I and IV, but not promoter IXa, via CREB family after BDNF-TrkB signaling is partially conserved between rodents and humans. A-C, Graphical representation of the conservation of previously described CRE elements in BDNF promoters I, IV, and IXa. Light blue shading represents the core sequence of the CRE element. $D-I$, Primary neurons were transfected at 6 DIV with different rat and human BDNF promoter constructs (denoted as rBDNF and hBDNF, respectively) together with EGFP or $A$-CREB overexpression constructs $(\boldsymbol{D}, \boldsymbol{F}, \boldsymbol{H})$ or with wild-type (WT) BDNF promoter construct or respective CRE-mutated promoter constructs $(\boldsymbol{E}, \boldsymbol{G}, \boldsymbol{I})$ as shown below the graph. At 7 DIV, neurons were treated with 50 ng/mI BDNF for different time periods or left untreated as indicated, and promoter activity was measured using luciferase reporter assay. Promoter activity was calculated relative to the respective promoter activity in cells transfected with EGFP and not treated with $\operatorname{BDNF}(\boldsymbol{D}, \boldsymbol{F}, \boldsymbol{H})$ or as fold induction relative to the respective promoter activity in untreated cells $(\boldsymbol{E}, \boldsymbol{G}, \boldsymbol{I})$. Average of three or four independent experiments $(\boldsymbol{D}, \boldsymbol{F}, \boldsymbol{H}: n=4 ; \boldsymbol{E}, \boldsymbol{G}, \boldsymbol{I}: n=3)$ is shown. Error bars indicate SEM. Statistical significance between the inductions of respective promoter constructs in EGFP and A-CREB-overexpressing cells at respective time points: ${ }^{* * *} p<0.001 ;{ }^{* *} p<0.01 ;{ }^{*} p<0.05$ (paired two-tailed $t$ test, corrected for multiple comparisons using Holm-Sidak method).

signaling is similar between rat and human. For that, we used luciferase reporter assay with reporter constructs containing human or rat respective promoter regions (Fig. 11).

While the core CRE element in BDNF promoter I is conserved between rodents and human, its flanking region differs (Fig. $11 A$ ). Therefore, we first investigated the regulation of rat and human BDNF promoter I 5' region in response to BDNF-TrkB signaling (Fig. 11D). Overexpression of A-CREB reduced the TrkB signaling-dependent activation of both rat and human $B D N F$ promoter I 5'. Notably, the effect of A-CREB was more prominent on the activation of human BDNF promoter I $5^{\prime}$, in which case the activity of the promoter region decreased from $\sim 15$-fold to $\sim 8.7$-fold ( $p=0.0165$ ) after $4 \mathrm{~h}$, and from $\sim 26$-fold to $\sim 12$-fold ( $p=0.0004$ ) after $8 \mathrm{~h}$ BDNF-TrkB signaling. In addition, we found that mutating the CRE site in the promoter I 5 ' only slightly decreased the TrkB-induced levels of promoter activity of both human and rat BDNF promoter region (Fig. $11 E$ ). Together, our data show that the activation of human $B D N F$ promoter I in response to BDNF-TrkB signaling is slightly more dependent on CREB family transcription factors than the rat ortholog, but not via CRE element located in the proximal promoter.

Next, we examined the regulation of $B D N F$ promoter IV. The well-described CRE element in BDNF promoter IV has a murine 
linage-specific single nucleotide difference between rat and human (GCACGTCA vs TCACGTCA; Fig. 11B), which could affect CREB family-dependent regulation of the promoter activity. Overexpression of A-CREB reduced the basal activity of both rat and human $B D N F$ promoter IV $\sim 1.3$-fold $(p=0.0100)$ and $\sim 1.5$-fold ( $p=0.0793$ ), respectively (Fig. $11 F$ ). Interestingly, rat $B D N F$ promoter IV was more inducible than the human ortholog, as both at 4 and $8 \mathrm{~h}$ of BDNF treatment the induction of rat BDNF promoter IV activity in EGFP-expressing cells was $\sim 1.5$-fold higher than its human counterpart. After BDNF-TrkB signaling, the overexpression of A-CREB greatly reduced the activity of rat $B D N F$ promoter IV at all time points (Fig. $11 F$ ) similarly to the previous experiment (Fig. 10A). Likewise, although with a smaller effect, the activation of human $B D N F$ promoter IV in response to BDNF-TrkB signaling was reduced from $\sim 1.2$-fold to $\sim 0.78$-fold ( $p=0.0103$ ) after $2 \mathrm{~h}$, from $\sim 1.6$-fold to $\sim 1.2$-fold $(p=0.0295)$ after $4 \mathrm{~h}$, and from $\sim 1$.9-fold to $\sim 1.7$ fold $(p=0.3809)$ after $8 \mathrm{~h}$ BDNF treatment by A-CREB overexpression.

To determine whether the difference in the activation of rat and human BDNF promoter IV results from the singlenucleotide difference in the CRE element, we made reporter constructs where we introduced human CRE element into rat $B D N F$ promoter region and rat CRE element into human $B D N F$ promoter region (Fig. $11 G$ ). We found that the single nucleotide variation in the CRE element did not significantly contribute to the difference in the inducibility of the promoter IV region. We also determined that mutating the CRE element in both rat and human BDNF promoter IV completely abolished the induction of the promoter in response to BDNFTrkB signaling. Collectively, stronger activation of $B D N F$ promoter IV in response to BDNF-TrkB signaling seems to be mediated by CREB family transcription factors, but the difference in the activation of rat and human respective promoters is not due to the single nucleotide difference in the CRE element.

In human BDNF promoter IXa, a functional CRE element responsible for neuronal activity-dependent induction of the promoter has been described (Pruunsild et al., 2011). However, there is a 2 nucleotide difference in the CRE element between rat and human (TGACGGCG vs TGACAGCA; Fig. 11C). We studied the induction of BDNF promoter IXa, and we found that while the rat promoter IXa region is not inducible in response to BDNF-TrkB signaling, the respective human promoter region is, with up to $\sim 2.3$-fold increase in the promoter activity after $8 \mathrm{~h}$ of BDNF treatment (Fig. 11H). Notably, overexpression of A-CREB decreased TrkB signaling-induced activity of the human BDNF promoter IXa by $\sim 1$.2-fold to 1.4 -fold. We next localized the regulatory elements required for the induction of the human $B D N F$ promoter IXa to the 112 bp 3' region of the promoter, which showed similar activation in response to BDNF-TrkB signaling as the full-length 908 bp promoter region (Fig. 11I). Remarkably, mutating the CRE element completely abolished the activation of the promoter, indicating that the CRE element is the main mediator of TrkB signaling-dependent activation of human $B D N F$ promoter IXa. Collectively, we found remarkable differences in the regulation of $B D N F$ promoter IXa between rat and human, as the activity of the rat BDNF promoter IXa is not inducible in response to BDNF-TrkB signaling, whereas the activity of the human ortholog is through a primate lineage-specific CRE element.

\section{CREB transcription factor mediates the early induction of exon IIc-, IV-, VI-, and IXa-containing BDNF transcripts after BDNF-TrkB signaling}

Our results with overexpression of A-CREB and treatment with CCII indicated that CREB family is involved in the BDNF transcriptional autoregulation, but neither of the experiments was specific to CREB. Since the dimerization of A-CREB is based on CREB leucine zipper domain, it can form dimers with the transcription factors that also dimerize with CREB (e.g., possibly with all the members of the CREB family). Also, CBP/p300 can interact with several transcription factors via KIX domain. Therefore, we next wanted to determine the role of CREB in BDNF transcriptional autoregulation. We suppressed CREB1 mRNA expression using CRISPR interference, treated neurons with BDNF at $8 \mathrm{DIV}$, and used qRT-PCR to measure the expression levels of $B D N F$ transcripts (Fig. 12).

First, we determined the efficiency of CREB1 knockdown in our cultured neurons (Fig. 12A). We found that dCas9-KRAB targeted to the $C R E B 1$ promoter region reduced $C R E B 1 \mathrm{mRNA}$ levels $\sim 4.5$-fold ( $p=0.00005$ ) (Fig. 12A), which also reflected in significant reduction of CREB protein level (data not shown). Next, we studied the influence of $C R E B$ knockdown on BDNF transcriptional autoregulation. Interestingly, suppressing $C R E B 1$ expression abolished the early induction of total BDNF expression levels, as after $1 \mathrm{~h}$ of BDNF-TrkB signaling, the induced levels of total $B D N F$ mRNA reduced from $\sim 2$.9-fold to $\sim 1.2$-fold $(p=0.0001)$ in CREB1 knockdown cells. After $3 \mathrm{~h}$ of BDNF treatment, the induction of total $B D N F$ mRNA decreased from $\sim 11$-fold to $\sim 9$-fold ( $p=0.0003$ ), but no difference in the induced levels was observed after $6 \mathrm{~h}$ of BDNF treatment. The induced levels of BDNF transcripts containing exons I and III were not significantly affected by the knockdown of $C R E B 1$. In contrast, CREB knockdown reduced the induced levels of BDNF transcripts containing exon IV and IXa from $\sim 5$.5-fold to $\sim 1.5$ fold ( $p=0.0002$ ) and from $\sim 8$-fold to $\sim 3.6$-fold $(p=0.0035)$, respectively, after $1 \mathrm{~h}$ of BDNF treatment. Also, CREB1 knockdown reduced the induced levels of $B D N F$ transcripts containing exon IV from $\sim 13$-fold to $\sim 7.7$-fold ( $p=0.00008$ ) after $3 \mathrm{~h}$ of BDNF treatment. Furthermore, CREB1 knockdown also slightly decreased the induced levels of exon IIc- and VI-containing $B D N F$ transcripts after $1 \mathrm{~h}$ of BDNF treatment: from $\sim 1$. 4 -fold to $\sim 1.0$-fold $(p=0.0007$ ) and from $\sim 1.8$-fold to $\sim 1$.4-fold ( $p=$ 0.0013 ), respectively. Interestingly, we also observed a slight $\sim 1$.3-fold upregulation of the basal expression level of both exon III- and exon VI-containing BDNF transcripts $(p=0.0256$ and $p=0.0327$, respectively). Together, our results show that CREB transcription factor is required for the early induction of exon IIc-, IV-, VI-, and IXa-containing BDNF transcripts, but only for the later induction of exon IV-containing $B D N F$ transcripts after BDNF-TrkB signaling.

In contrast to the specific effect of CREB1 knockdown on $B D N F$ exon IV-containing transcripts and only on the early induction of exon IIc, VI-, and IXa-containing transcripts, our results obtained with overexpression of A-CREB (Figs. 2, 3), and using CCII and E1A overexpression (Figs. 5, 6) indicated the involvement of CREB family in the regulation of most BDNF transcripts at $3 \mathrm{~h}$ BDNF treatment. Notably, it has been shown that the transcription factors within CREB family can compensate for each other (Hummler et al., 1994; Mantamadiotis et al., 2002; Díaz-Ruiz et al., 2008; Lemberger et al., 2008; Aguado et al., 2009; Gundersen et al., 2013), so it is possible that other CREB family members could have rescued the BDNF induction in CREB1 knockdown neurons. Therefore, to investigate how 

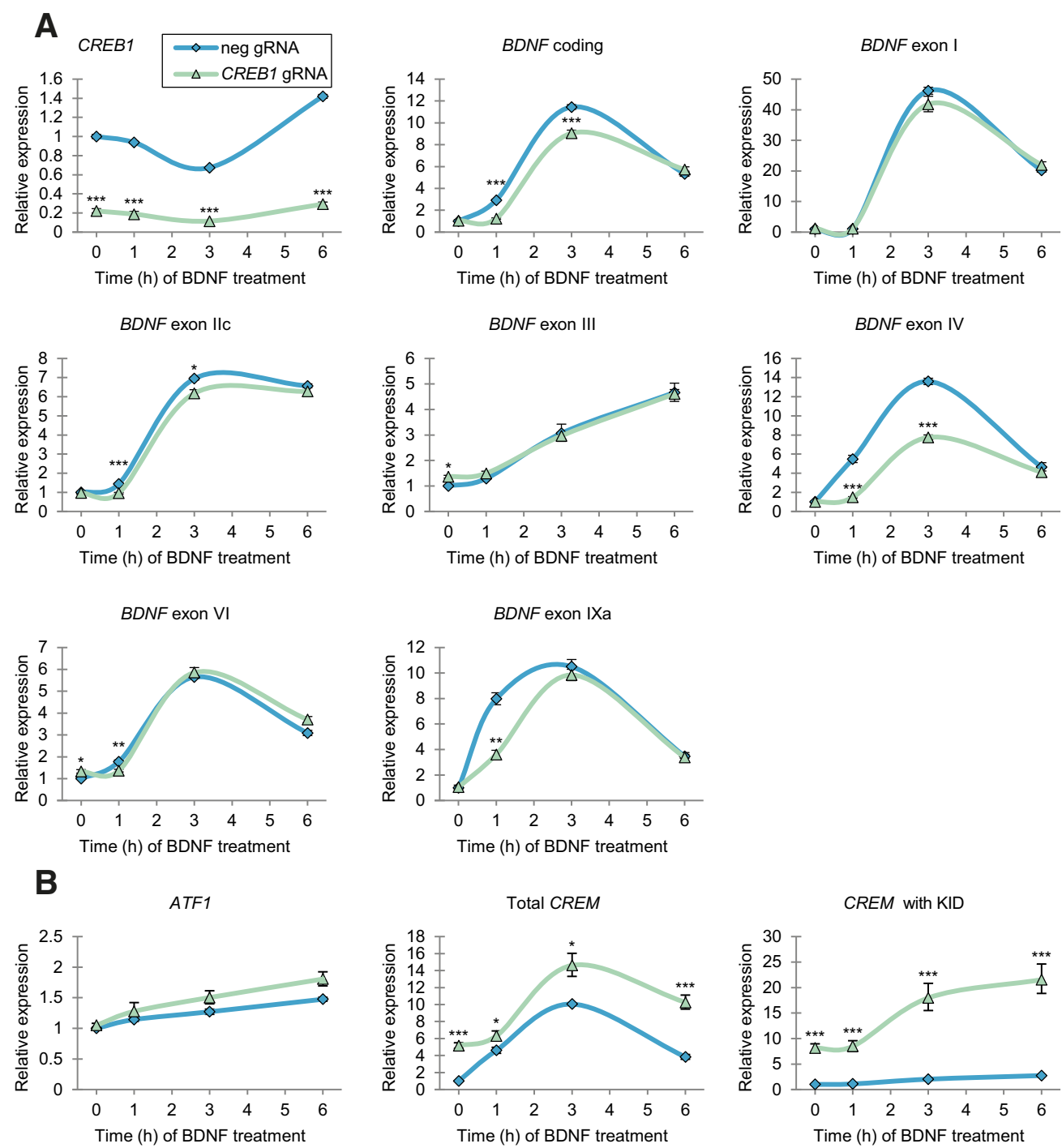

Figure 12. CREB is necessary for the early induction of exon IIC, IV-, VI-, and IXa-containing BDNF transcripts after BDNF-TrkB signaling. Primary neurons were transduced at 0 DIV with lentiviral particles coding for dCas9-KRAB, and (REB1 gRNA or negative gRNA (neg gRNA). At 8 DIV, neurons were treated with $50 \mathrm{ng} / \mathrm{ml}$ BDNF for the indicated time periods. Expression levels of CREB1, total $B D N F(B D N F$ coding), different $B D N F$ transcripts $(\boldsymbol{A})$ and other CREB family members $(\boldsymbol{B})$ were measured using qRT-PCR. The expression level of respective transcripts in cells transduced with dCas9-KRAB and negative gRNA-encoding lentiviral particles and not treated with BDNF was set as 1. Average of six independent experiments $(n=6)$ is shown. Error bars indicate SEM. Statistical significance between the respective transcript levels in cells overexpressing negative gRNA and CREB1 gRNA at respective time points: ${ }^{* * *} p<0.001$; ${ }^{* *} p<0.01 ;{ }^{*} p<0.05$ (paired two-tailed t test, corrected for multiple comparisons using Holm-Sidak method).

BDNF-TrkB signaling and suppressing CREB1 levels influence the expression of ATF1 and CREM, we measured their mRNA levels using qRT-PCR (Fig. 12B).

We found that $A T F 1$ was slightly induced in response to BDNF-TrkB signaling with maximal induction of $\sim 1.5$-fold after $6 \mathrm{~h}$ of BDNF treatment (Fig. 12B). Total CREM mRNA levels peaked at $\sim 10$-fold induction after $3 \mathrm{~h}$ of BDNF-TrkB signaling (Fig. 12B). In response to CREB1 knockdown, the expression of ATF1 mRNA did not change remarkably. However, the basal level of total CREM mRNA was $\sim 5.2$-fold $\left(p=2 \times 10^{-6}\right)$ higher in $C R E B$ knockdown neurons. Due to alternative splicing, the CREM gene produces several CREM protein isoforms, which can be transcriptional activators or repressors (Foulkes et al., 1991; Laoide et al., 1993). For example, ICER is a repressive CREM isoform that competes with CREB and provides a mechanism for downregulation of cAMP-dependent gene expression (Molina et al., 1993; Walker et al., 1998; Mioduszewska et al., 2003). To measure the levels of CREM activator forms, we used primers specific for CREM transcripts that contain KID domainencoding sequence (denoted as CREM with KID in Fig. 12B) and observed moderate induction in response to BDNF-TrkB signaling, peaking at $\sim 2.7$-fold induction after $6 \mathrm{~h}$ of BDNF treatment. We also saw $\sim 8.1$-fold $(p=0.00002)$ increase in the CREM activator form mRNA levels in untreated $C R E B$ knockdown cells (Fig. 12B).

As CREB1 knockdown greatly induced the expression of CREM activator forms, it is possible that the discrepancy between the results obtained with CREB1 knockdown and with A-CREB and E1A overexpression and CCII treatment could originate from CREM activator forms binding to CRE sites and thus regulating CRE-dependent transcription in cells where CREB1 is knocked down. Therefore, we next decided to elucidate the role of CREM in BDNF transcriptional autoregulation. For that, we knocked down the expression of CREM using CRISPR interference (Fig. 13). We determined that CREM mRNA expression level was reduced $\sim 1.8$-fold $(p=0.0048)$ and that the expression 

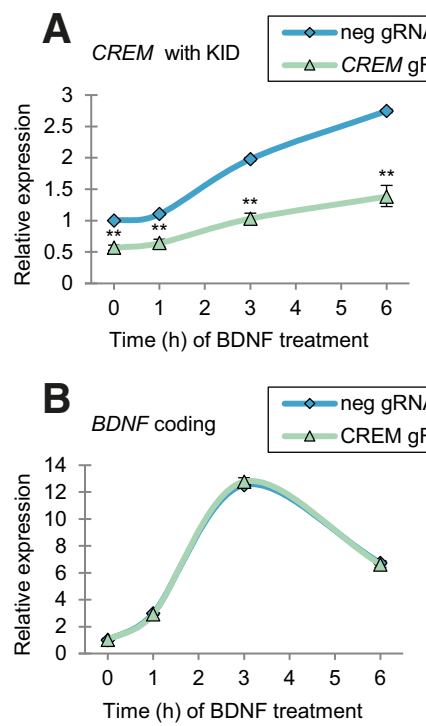

$B D N F$ exon III

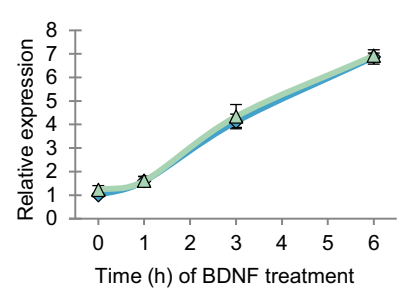

$B D N F$ exon IXa

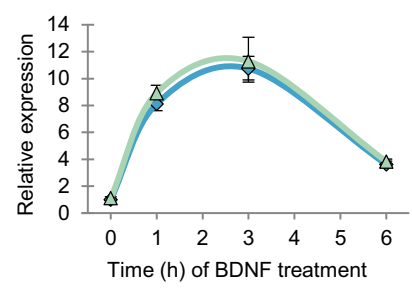

CREB1

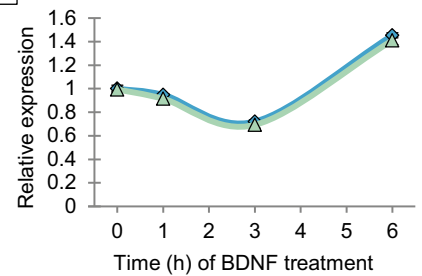

$B D N F$ exon I

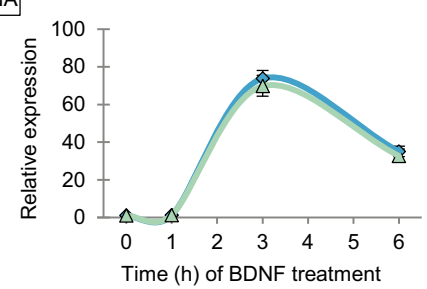

$B D N F$ exon IV

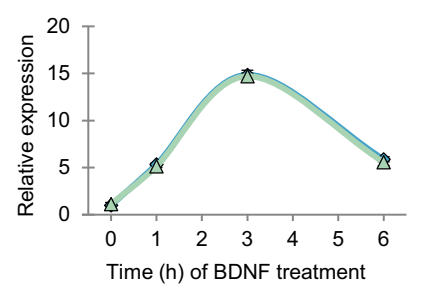

ATF1

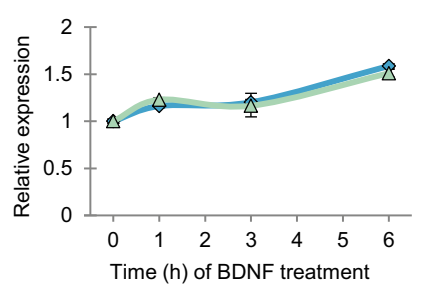

BDNF exon Ilc

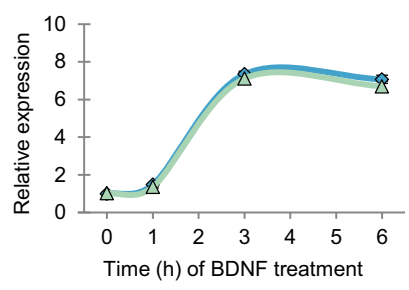

BDNF exon VI

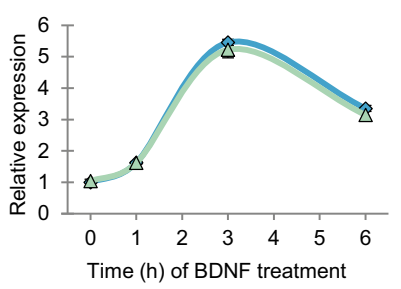

Figure 13. CREM is not involved in the induction of BDNF transcripts after BDNF-TrkB signaling. Primary neurons were transduced at 0 DIV with lentiviral particles coding for dCas9-KRAB and a combination of two CREM gRNAs or negative gRNA (neg gRNA). At 8 DIV, neurons were treated with $50 \mathrm{ng} / \mathrm{ml}$ BDNF for the indicated time periods. Expression levels of CREM with KID domain, CREB1 and $A T F 1(\boldsymbol{A})$, and total BDNF (BDNF coding) and different BDNF transcripts $(\boldsymbol{B})$ were measured using qRT-PCR. The expression level of respective transcripts in cells transduced with dCas9-KRAB and negative gRNA-encoding lentiviral particles and not treated with BDNF was set as 1. Average of five independent experiments $(n=5)$ is shown. Error bars indicate SEM. Statistical significance between the respective transcript levels in cells overexpressing negative gRNA and CREM gRNAs at respective time points: ${ }^{* *} p<0.01$ (paired two-tailed $t$ test, corrected for multiple comparisons using Holm-Sidak method).

level of $C R E B 1$ and $A T F 1$ did not change in response to CREM knockdown (Fig. 13A). Our data also showed that the induction of $B D N F$ transcripts was not affected by CREM knockdown (Fig. $13 B)$.

Finally, we investigated possible compensatory mechanisms between CREB and CREM by suppressing the expression of both CREB1 and CREM simultaneously. If CREM really compensated for CREB in BDNF autoregulation after CREB1 knockdown, one should observe a stronger effect on BDNF autoregulation in cells where both CREB1 and CREM are knocked down. In contrast, we observed similar results as was seen with only CREB1 knockdown; and no additional effect of CREM knockdown on BDNF gene expression after BDNF-TrkB signaling was detected (data not shown), indicating that CREM does not have compensatory effect on BDNF autoregulation in CREB1 knockdown cells. Together, our data show that, while CREM does not participate in BDNF transcriptional autoregulation, CREB is indispensable for the early induction of BDNF exon IIc, IV-, VI-, and IXacontaining transcripts after BDNF-TrkB signaling.

\section{Phosphorylated CREB binds to BDNF promoter IV after $B D N F-T r k B$ signaling and recruits $C B P$}

To determine whether CREB directly binds rat BDNF promoters in our cultured neurons and whether CREB binding changes after BDNF-TrkB signaling, we treated neurons with BDNF for $1 \mathrm{~h}$ and performed ChIP analysis with CREB and P-CREB antibodies. We then determined promoter enrichment using qPCR (Fig. 14).

As a positive control for CREB binding, we used $c$-Fos promoter, which showed $\sim 0.31 \%(p=0.0130)$ and $\sim 0.16 \%(p=$ 0.0172 ) of input enrichment in untreated and BDNF-treated cells, respectively (Fig. 11A). Rat BDNF promoters I, II, III, and IXa showed no remarkable CREB binding compared with the negative control rat BDNF $3^{\prime}$ untranslated region. CREB binding to rat $B D N F$ promoter IV showed $0.025 \%(p=0.2223$, uncorrected $p=0.0410)$ of input enrichment in nontreated cells, and $0.022 \%(p=0.2467$, uncorrected $p=0.0461)$ of input enrichment in BDNF-treated cells. Slight $0.019 \%(p=0.4438$, uncorrected $p=0.1364)$ and $0.015 \%$ of input enrichment $(p=0.3647$, uncorrected $p=0.2007$ ) was also detected for the rat BDNF 
A

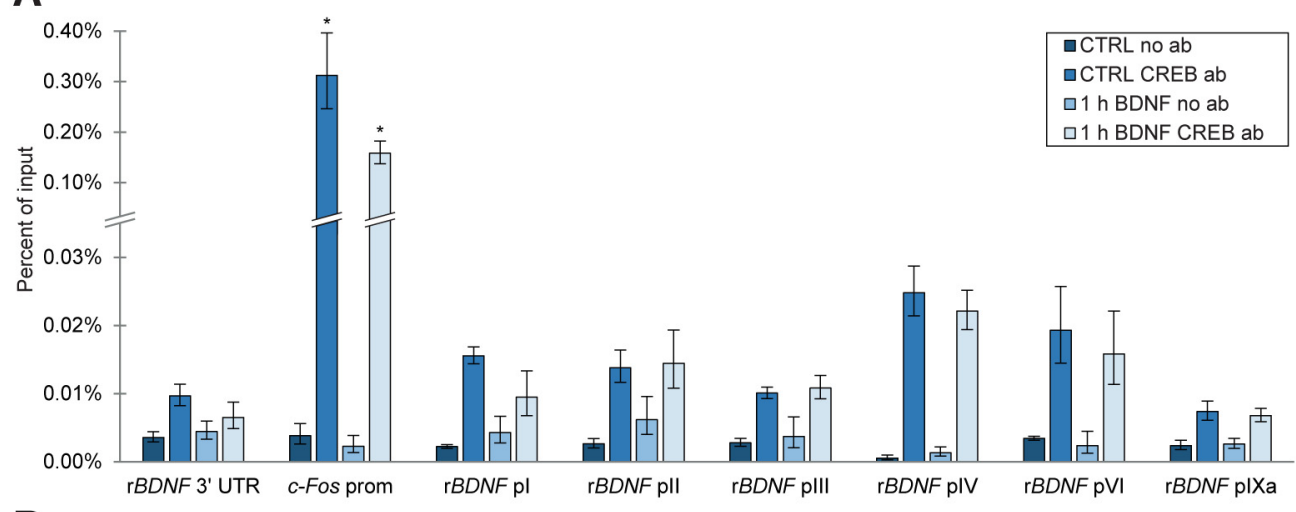

B

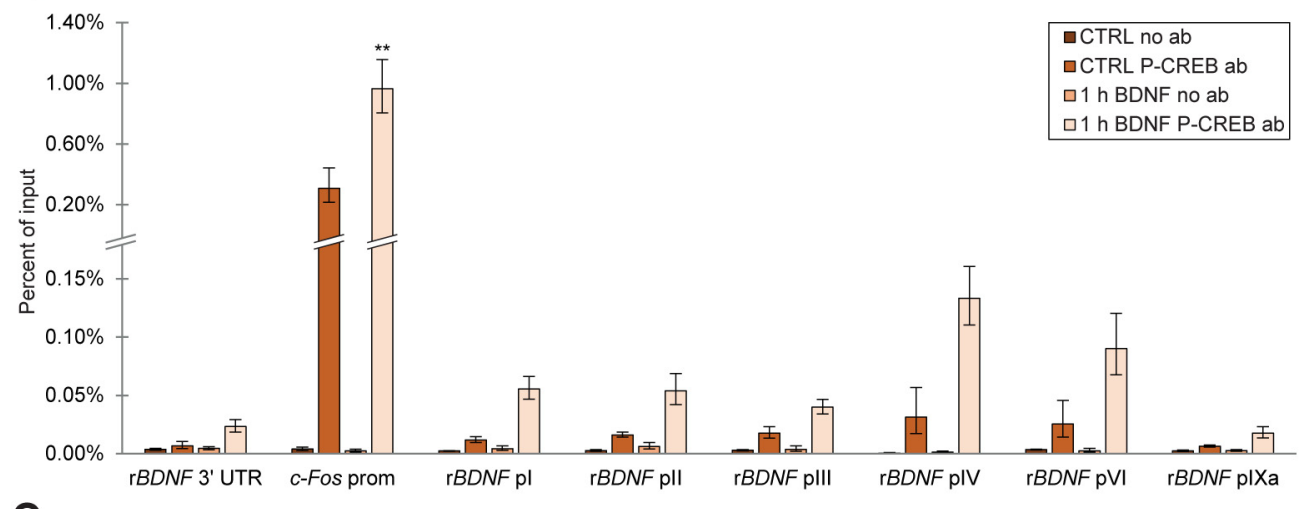

C

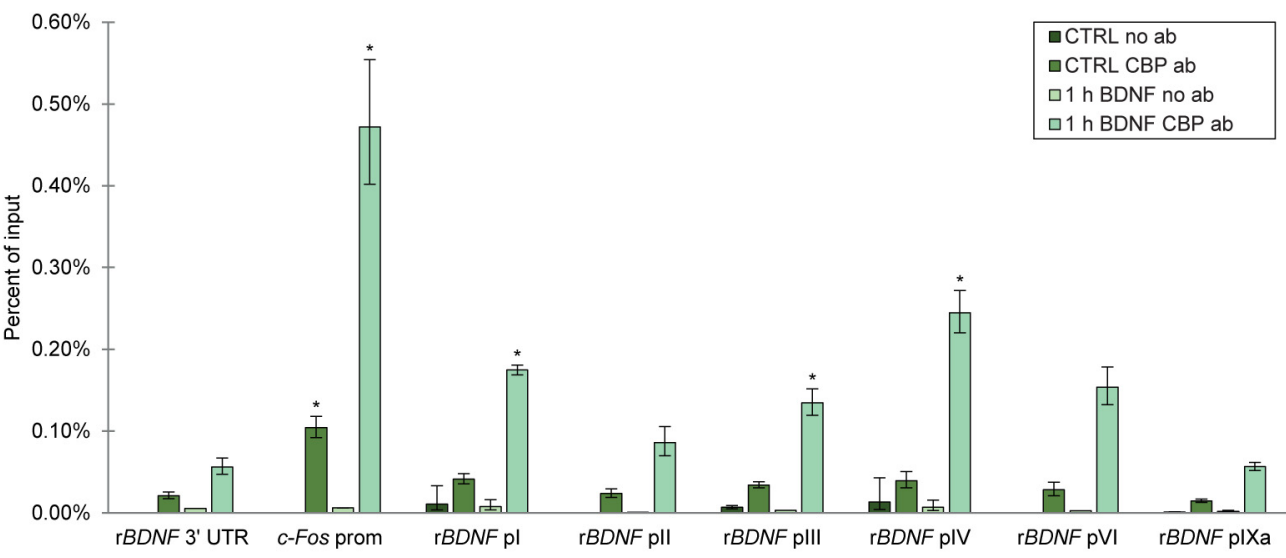

Figure 14. CREB binds to BDNF promoter IV, is phosphorylated after BDNF-TrkB signaling, and recruits CBP. Primary neurons were treated at 7 DIV with $50 \mathrm{ng} / \mathrm{ml}$ BDNF for $1 \mathrm{~h}$ or left untreated (CTRL) and then subjected to ChIP assay using CREB ( $(A)$, phospho-Ser-133 CREB (P-CREB) $(B)$, or CBP $(\boldsymbol{C})$ antibodies (ab). DNA enrichment of $c-$ Fos promoter, different rat $B D N F(r B D N F)$ promoter ( $p$ ) regions, and rat BDNF $3^{\prime}$ untranslated region (rBDNF $3^{\prime}$ UTR) was measured using qPCR. DNA enrichment is represented as percentage of input. Average of three or four ( $\boldsymbol{A}, \boldsymbol{C}, n=4 ; \boldsymbol{B}, n=3$ ) independent experiments is shown. Error bars indicate SEM. No antibody controls depict the same dataset in $\boldsymbol{A}$ and $\boldsymbol{B}$. Statistical significance is relative to the enrichment of rBDNF $3^{\prime}$ UTR region in respectively treated cells. Statistical analysis was not performed on no antibody controls. ${ }^{* *} p<0.01 ;{ }^{*} p<0.05$ (paired two-tailed $t$ test, corrected for multiple comparisons using Holm-Sidak method).

promoter VI in untreated cells and after BDNF treatment, respectively.

Since we already established that CREB is phosphorylated after TrkB signaling (Fig. 4) we also investigated the binding of phospho-Ser-133 CREB using ChIP analysis (Fig. 14B). In untreated and BDNF-treated neurons, we observed $\sim 0.31 \%$ ( $p=$ 0.2553 ) and $\sim 0.97 \%$ ( $p=0.0063$ ) of input enrichment, respectively, at $c$-Fos promoter region for phospho-CREB. No remarkable binding of phospho-CREB was detected to rat BDNF promoters in nontreated cells. However, in response to BDNFTrkB signaling, phospho-CREB binding increased $\sim 3$-fold to $\sim 4$-fold at every region measured, including at the negative control region. As we did not detect CREB binding to rat BDNF promoters I, II, III, and IXa, it is plausible that the observed increase in phospho-CREB binding to these promoters in BDNFtreated cells was an artifact due to overall higher phospho-CREB protein levels in neurons, and not a functional recruitment of phospho-CREB. In contrast, in BDNF-treated neurons, phosphoCREB binding showed notable $0.13 \%(p=0.1333$, uncorrected $p=0.0339)$ and $0.09 \%(p=0.1392$, uncorrected $p=0.0787)$ of input enrichment at rat BDNF promoters IV and VI, respectively. Together, our results indicate that CREB binds to BDNF pro- 


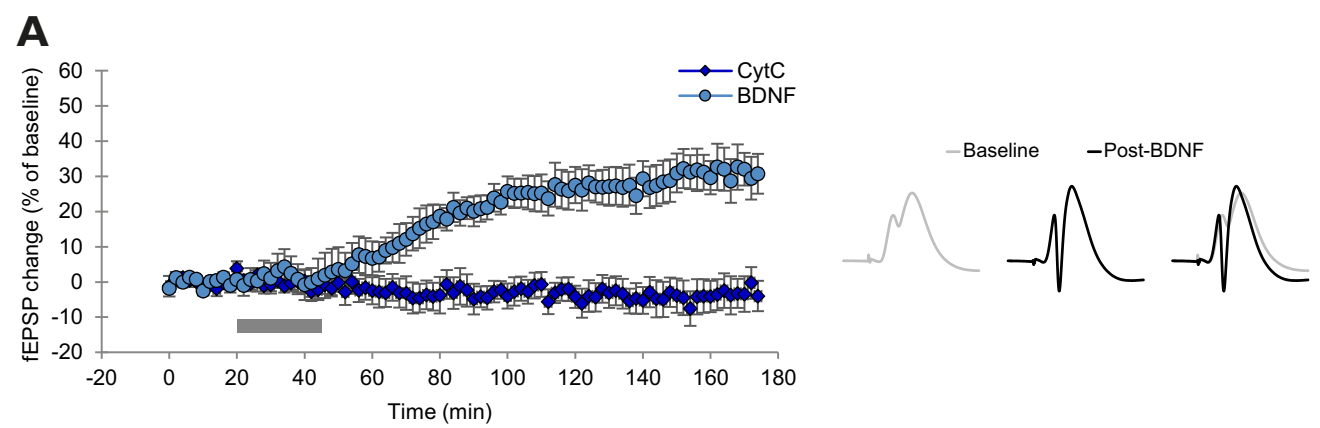

B
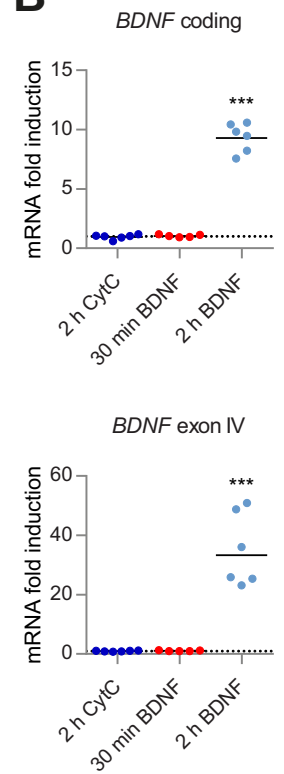

$B D N F$ exon I

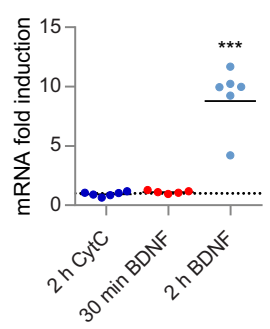

$B D N F$ exon $\mathrm{VI}$

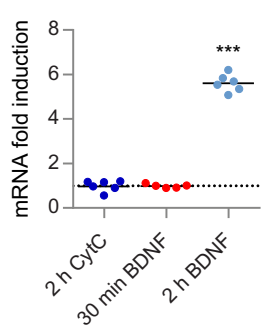

$B D N F$ exon IIc

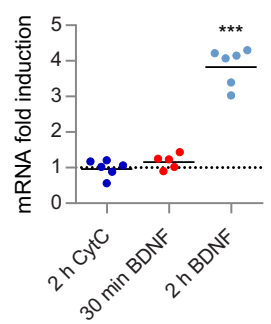

$B D N F$ exon IXa

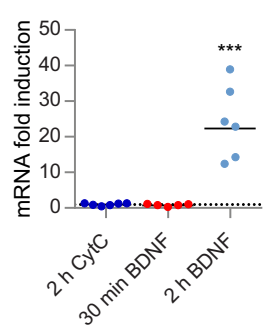

Figure 15. BDNF infusion into rat hippocampus elicits enhanced synaptic transmission and induces the expression of all BDNF transcripts in the hippocampal dentate gyrus region. $A$, Time course plots of fEPSP slope recorded before and after BDNF or CytC infusion (left) and sample field potential traces (right). A total of $2 \mu \mathrm{l}(1 \mu \mathrm{g} / \mu \mathrm{l}$ ) of BDNF or CytC was infused over $25 \mathrm{~min}$ into the dentate gyrus over the period indicated by the gray bar. The evoked fEPSP slope change is expressed in percentage of baseline. Depicted values are mean \pm SEM of 6 independent animals $(n=6$ for both groups). $\boldsymbol{B}$, The expression levels of different BDNF transcripts was measured from dentate gyri of both ipsilateral and contralateral hemisphere using qRT-PCR. The expression levels of $B D N F$ transcripts were normalized to the HPRT1 expression levels and are depicted as fold induction compared with the respective transcript expression levels in the contralateral hemisphere. Dots represent data from all the experiments. Horizontal line indicates the geometric mean of 5 or 6 independent animals $(n=5$ or 6$)$. Dashed line indicates the level of respective transcripts in the contralateral side and was set as 1 (no induction). Statistical significance between the respective transcript levels in dentate gyri of ipsilateral and contralateral hemispheres: ${ }^{* * *} p<0.001$ (paired two-tailed $t$ test, corrected for multiple comparisons using Holm-Sidak method).

moter IV and the binding of phosphorylated CREB increases after BDNF-TrkB signaling.

To clarify whether the requirement for $\mathrm{CBP} / \mathrm{p} 300$ (Figs. 5, 6) is because of direct binding of CBP to BDNF proximal promoters, we also performed CBP ChIP with an antibody that does not cross-react with $\mathrm{p} 300$ and measured CBP binding to BDNF promoters with qPCR (Fig. 14C). We determined that CBP enrichment at $c$-Fos promoter was $\sim 0.10 \%(p=0.0354)$ of input in untreated neurons and $\sim 0.47 \%$ ( $p=0.0377$ ) of input in BDNFtreated neurons. In untreated cells, CBP was not remarkably enriched at $B D N F$ promoter regions compared with the enrichment at the negative control region BDNF $3^{\prime}$ UTR. However, after BDNF treatment we saw CBP binding to BDNF promoters I, III, and IV, and possibly to promoter VI, showing $\sim 0.18 \%$ ( $p=$ $0.0377), \sim 0.14 \%(p=0.0377), \sim 0.25 \%(p=0.0343)$, and $\sim 0.15 \%$ ( $p=0.0587$, uncorrected $p=0.0199$ ) of input enrichment, respectively. Since we did not detect such extensive binding of P-CREB to BDNF promoters I and III (and possibly VI), it is plausible that $C B P$ is recruited to these $B D N F$ promoters via transcription factors other than CREB. Collectively, our results show that CREB binds to BDNF promoter IV, is phosphorylated after BDNF-TrkB signaling, and recruits CBP to increase BDNF expression.

\section{All $B D N F$ transcripts are induced in the adult rat hippocampus in vivo after BDNF-TrkB signaling}

It has previously been shown that brief infusion of BDNF protein into adult rat hippocampus results in transcription-dependent LTP (Messaoudi et al., 2002), which requires MAPK pathway activation leading to CREB phosphorylation (Ying et al., 2002). Furthermore, infusion of BDNF into rat hippocampus induces the expression of $B D N F$ exon IV-containing transcripts (Wibrand et al., 2006), whereas the expression of other $B D N F$ transcripts has not been studied. To determine whether the BDNF transcriptional autoregulation pattern we have described here in cultured neurons is also present in vivo, we infused BDNF protein into adult rat hippocampus to elicit BDNF-LTP and measured the expression levels of different $B D N F$ transcripts in the dentate gyrus region of the hippocampus using qRT-PCR (Fig. 15).

Local infusion of BDNF but not CytC into dentate gyrus elicited an $\sim 30 \%$ increase in the fEPSP slope (Fig. 15A), indicating the functionality of our BDNF-induced LTP paradigm. In rats 
infused with CytC, we did not detect induction of any BDNF transcripts $2 \mathrm{~h}$ after the infusion (Fig. 15). Likewise, $30 \mathrm{~min}$ after $\mathrm{BDNF}$ infusion, the expression levels of different BDNF transcripts were similar to the expression levels in the contralateral hemisphere. Notably, $2 \mathrm{~h}$ after the infusion of BDNF protein, the expression of all the $B D N F$ transcripts was induced. Total $B D N F$ mRNA level increased $\sim 9.3$-fold $\left(p=5 \times 10^{-7}\right)$, and the strongest inductions were seen for $B D N F$ exon IV- and IXa-containing transcripts, which were induced $\sim 33.3$-fold $\left(p=6 \cdot 10^{-6}\right)$ and $\sim 22.4$-fold $\left(p=4 \times 10^{-5}\right)$, respectively, after $2 \mathrm{~h}$ of BDNF infusion. Moderate induction of $\sim 8.8$-fold $\left(p=9 \times 10^{-5}\right)$ and $\sim 5.6$-fold $\left(p=7 \times 10^{-8}\right.$ ) was seen for BDNF exon I- and VIcontaining transcripts, respectively, and exon IIc- and IIIcontaining $B D N F$ transcripts showed slight but statistically significant $\sim 3.8$-fold $\left(p=9 \times 10^{-6}\right)$ and $\sim 2.3$-fold $(p=3 \times$ $10^{-6}$ ) induction, respectively. Collectively, our results indicate that extensive BDNF transcriptional autoregulatory loop also occurs in vivo, encompassing all the major BDNF transcripts.

\section{Discussion}

The early induction of total BDNF mRNA levels in response to neuronal activity has been shown to be independent of protein synthesis (Hughes et al., 1993; Castrén et al., 1998). Additionally, the neuronal activity-dependent induction of BDNF exon IVcontaining transcripts has been shown to be protein synthesisindependent (Lauterborn et al., 1996; Tao et al., 1998), while the induction of BDNF transcripts containing exon I and II depends on protein synthesis (Lauterborn et al., 1996). Here, we have determined the requirement for protein synthesis in BDNF transcriptional autoregulation. Our results show that the induction of most BDNF transcripts upon BDNF-TrkB signaling depends on protein synthesis, and only the early induction of $B D N F$ exon IIc-, IV-, and VI-containing transcripts is partially protein synthesis-independent. The de novo protein synthesis-independent early induction of these BDNF transcripts could be explained by their regulation via CREB family proteins that are constitutively expressed and whose activity is regulated through post-translational mechanisms (for review, see Johannessen et al., 2004). Notably, the requirement for protein synthesis suggests that, in addition to constitutively expressed proteins, inducible transcription factors are necessary for the BDNF transcriptional autoregulation. For example, we have previously shown that AP-1 transcription factors regulate $B D N F$ gene expression after TrkB signaling (Tuvikene et al., 2016).

It is well known that CREB transcription factor family regulates the transcription of $B D N F$, especially the activation of $B D N F$ promoter IV (Shieh et al., 1998; Tao et al., 1998; Cha-Molstad et al., 2004; Hong et al., 2008; Pruunsild et al., 2011; West et al., 2014), but also BDNF promoter I (Tabuchi et al., 2002; Benito et al., 2011) in response to neuronal activity. Here, we have discovered that the CREB family is also a major regulator of $B D N F$ gene expression after TrkB signaling. We show that USF and NFAT transcription factor families, which have previously been shown to be involved in neuronal activity-regulated BDNF gene expression (Chen et al., 2003; Vashishta et al., 2009; Pruunsild et al., 2011 ), do not significantly contribute to $B D N F$ gene induction after TrkB signaling. This implies that the mechanisms of $B D N F$ gene expression triggered by BDNF-TrkB signaling and neuronal activity differ. Notably, none of the dominant-negative proteins we used in our experiments completely abolished the induction of $B D N F$ transcription after TrkB signaling, indicating that there are other, yet to be determined transcription factors involved in the BDNF autoregulation. Considering the profound effect of A-CREB overexpression on the expression of all major BDNF transcripts, one could hypothesize that important de novo synthesized transcription factors regulating $B D N F$ gene expression are indeed CREB target genes. It is also plausible that CREB acts as a nucleating factor for other, de novo synthesized transcription factors to bind the BDNF promoters, as it has been proposed for BDNF promoter IV (Hong et al., 2008).

It is important to note the possible TrkB signaling-dependent component in the regulation of $B D N F$ gene expression in paradigms using membrane depolarization. It has been described that neuronal activity induces BDNF secretion (for review, see Park and Poo, 2013), which could consequently activate TrkB receptors, possibly giving rise to the BDNF-TrkB autoregulatory loop. In the light of our results, it is plausible that neuronal activity induces $B D N F$ expression and the subsequent BDNF-TrkB signaling maintains the expression of $B D N F$ via an autonomous pathway. For example, the impairment of BDNF induction after kainic acid infusion in TrkB.T1 overexpressing mice implies that BDNF-TrkB signaling is required for proper $B D N F$ expression in the brain after neuronal activity (Saarelainen et al., 2001).

It has been reported that CREB-mediated regulation of gene expression plays an important role in the proper development of the nervous system and neurons (Lonze and Ginty, 2002). Therefore, the effect of overexpressing dominan-negative CREB family protein, A-CREB, on the development and maturation of neurons in culture is an important question that should be kept in mind when interpreting our results. Results of our experiments with long-term overexpression of A-CREB are in good accordance with the results of our experiments with acute treatment of CREB-CBP interaction inhibitor (CCII), supporting the notion that CREB family regulates BDNF transcriptional autoregulation independent of potential developmental changes. Our results also showed the requirement for CREB family and its interaction with CBP/p300 for the early induction of BDNF gene after TrkB signaling. Notably, at a later phase, after $6 \mathrm{~h}$ of BDNF treatment, neither A-CREB nor CCII had an influence on BDNF gene induction. Furthermore, knockdown of CREB1 expression also affected only the early induction of BDNF exon IIc-, IV-, VI-, and IXa-containing transcripts. This indicates that, while the early phase of TrkB signaling-dependent induction of BDNF in neurons is regulated by CREB-CBP/p300 complex, the late phase of induction is regulated in a CREB family-independent manner. In contrast, inhibition of $\mathrm{CBP} / \mathrm{p} 300$ by overexpressing E1A strongly decreased both the early and late phase of $B D N F$ gene induction after TrkB signaling. This could be explained by the fact that numerous other transcription factors in addition to CREB family proteins recruit $\mathrm{CBP} / \mathrm{p} 300$ to regulate gene expression (Bedford et al., 2010). Furthermore, while we only noted CREB binding to $B D N F$ promoter IV and possibly VI, we saw CBP binding to various $B D N F$ promoters: promoter I, III, IV, and possibly VI. This further suggests that, while CREB recruits CBP to BDNF promoter IV and possibly to promoter VI, other transcription factors recruit $\mathrm{CBP}$ to other $B D N F$ promoters.

The CREB family has been associated with the regulation of $B D N F$ in both rodents and humans. Here, we found that, although the general activation of BDNF promoters I and IV in response to BDNF-TrkB signaling was conserved between human and rat, subtle differences existed in their regulation by CREB family proteins. The activation of human $B D N F$ promoter I was slightly more dependent on CREB family transcription factors than the rat ortholog. Furthermore, we found that the human $B D N F$ promoter IV region was less inducible than the 
respective rat counterpart, and our results indicate potential CREB family-dependent differences in the regulation of this promoter between rat and human. It is notable that the murinespecific single nucleotide difference, which is absent in other major mammalian clades in BDNF promoter IV CRE element, does not remarkably change the activity of the promoter in cultured rat neurons. On the contrary, the two-nucleotide difference in the CRE element between human and rat BDNF promoter IXa seems to be responsible for the BDNF-TrkB signaling-dependent activation of human promoter, which is absent for the rat ortholog. As we have found a profound difference in the regulation of $B D N F$ promoter IXa region in rat and human, the regulation of the human BDNF promoter IXa after BDNF-TrkB signaling in the endogenous context will need to be clarified in future research.

Importantly, our data suggest the existence of distal enhancer elements for $B D N F$ gene regulation after TrkB signaling. First, overexpression of A-CREB did not decrease the induction from $B D N F$ proximal promoters II, III, and VI in promoter assays, whereas overexpression of A-CREB reduced the induction of all these $B D N F$ transcripts in the endogenous context. Second, the expression of rat endogenous $B D N F$ exon IXa-containing transcripts is induced rapidly in response to BDNF-TrkB signaling, whereas the BDNF proximal promoter IXa was not inducible in our promoter activity assays. Third, functional CRE elements in rodents have only been described in BDNF promoters I and IV, and we also discovered that the CRE element in BDNF promoter IV was necessary for the activation of the proximal promoter region. On the contrary, our results using overexpression of A-CREB, treatment with CCII, and overexpression of E1A showed a strong effect on the induction of all the investigated $B D N F$ transcripts. Moreover, CBP has been widely associated with enhancer regions (Kim et al., 2010). Notably, it has been reported that the binding of CREB coactivator CRTC1 is preferential to promoters containing a TATA box (Parra-Damas et al., 2017) for the interaction with general transcription factors (Conkright et al., 2003). As we found in our work that neither CRTC1 nor other CRTC family coactivators are required, while $\mathrm{CBP}$ is necessary for the BDNF transcriptional autoregulation, it could imply that BDNF gene expression is regulated by a distal enhancer region, not only by the proximal promoter regions. Together, these contradictions imply that important regulatory areas responsible for BDNF-TrkB signaling-dependent $B D N F$ induction are located outside of the proximal promoter regions, possibly even outside the BDNF gene. As we noted an effect on all measured BDNF transcripts with A-CREB, CCII, and E1A, it is plausible that there is a locus control region affecting the expression of the whole BDNF gene, and the cis-elements in proximal promoter regions provide fine-tuning of the expression of different $B D N F$ transcripts in response to TrkB signaling.

Dysregulation of BDNF expression in a brain region and cell type-specific manner has been implicated in various neurological and neurodevelopmental disorders and in various neurodegenerative diseases (Zuccato and Cattaneo, 2009; Autry and Monteggia, 2012; Tejeda and Díaz-Guerra, 2017). Although modulating BDNF levels could be successful in therapy, the challenge lies in controlling $B D N F$ expression in a precise spatiotemporal manner. It has been shown that uniform overexpression of BDNF in the excitatory neurons of the forebrain, including hippocampus and amygdala, causes anxiety-like behavior (Govindarajan et al., 2006). Additionally, increased levels of BDNF protein in PFC and hippocampus impairs working memory and fear conditioning, increases susceptibility to seizures, and also causes an anxiety-like phenotype (Papaleo et al., 2011). This has raised the need to ultimately enhance the transcription of $B D N F$ specifically in cells that express $B D N F$ under physiological conditions, to minimize serious side effects. The knowledge of how BDNF promoters are regulated in response to BDNF-TrkB signaling added by this study could provide solutions to the challenges of precisely adjusting BDNF levels in both health and disease.

\section{References}

Aguado F, Díaz-Ruiz C, Parlato R, Martínez A, Carmona MA, Bleckmann S, Ureña JM, Burgaya F, del Río JA, Schütz G, Soriano E (2009) The CREB/ CREM transcription factors negatively regulate early synaptogenesis and spontaneous network activity. J Neurosci 29:328-333.

Ahn S, Olive M, Aggarwal S, Krylov D, Ginty DD, Vinson C (1998) A dominant-negative inhibitor of CREB reveals that it is a general mediator of stimulus-dependent transcription of c-fos. Mol Cell Biol 18:967-977.

Aid T, Kazantseva A, Piirsoo M, Palm K, Timmusk T (2007) Mouse and rat BDNF gene structure and expression revisited. J Neurosci Res 85:525-535.

Aramburu J, Yaffe MB, López-Rodríguez C, Cantley LC, Hogan PG, Rao A (1999) Affinity-driven peptide selection of an NFAT inhibitor more selective than cyclosporin A. Science 285:2129-2133.

Autry AE, Monteggia LM (2012) Brain-derived neurotrophic factor and neuropsychiatric disorders. Pharmacol Rev 64:238-258.

Bambah-Mukku D, Travaglia A, Chen DY, Pollonini G, Alberini CM (2014) A positive autoregulatory $\mathrm{BDNF}$ feedback loop via $\mathrm{C} / \mathrm{EBP} \beta$ mediates hippocampal memory consolidation. J Neurosci 34:12547-12559.

Bannister AJ, Kouzarides T (1996) The CBP co-activator is a histone acetyltransferase. Nature 384:641-643.

Barco A, Marie H (2011) Genetic approaches to investigate the role of CREB in neuronal plasticity and memory. Mol Neurobiol 44:330-349.

Bedford DC, Kasper LH, Fukuyama T, Brindle PK (2010) Target gene context influences the transcriptional requirement for the KAT3 family of CBP and p300 histone acetyltransferases. Epigenetics 5:9-15.

Benito E, Valor LM, Jimenez-Minchan M, Huber W, Barco A (2011) cAMP response element-binding protein is a primary hub of activity-driven neuronal gene expression. J Neurosci 31:18237-18250.

Best JL, Amezcua CA, Mayr B, Flechner L, Murawsky CM, Emerson B, Zor T, Gardner KH, Montminy M (2004) Identification of small-molecule antagonists that inhibit an activator:coactivator interaction. Proc Natl Acad Sci U S A 101:17622-17627.

Bibel M, Barde YA (2000) Neurotrophins: key regulators of cell fate and cell shape in the vertebrate nervous system. Genes Dev 14:2919-2937.

Bittinger MA, McWhinnie E, Meltzer J, Iourgenko V, Latario B, Liu X, Chen $\mathrm{CH}$, Song C, Garza D, Labow M (2004) Activation of cAMP response element-mediated gene expression by regulated nuclear transport of TORC proteins. Curr Biol 14:2156-2161.

Bourtchuladze R, Frenguelli B, Blendy J, Cioffi D, Schutz G, Silva AJ (1994) Deficient long-term memory in mice with a targeted mutation of the cAMP-responsive element-binding protein. Cell 79:59-68.

Bramham CR, Messaoudi E (2005) BDNF function in adult synaptic plasticity: the synaptic consolidation hypothesis. Prog Neurobiol 76:99-125.

Breen ME, Mapp AK (2018) Modulating the masters: chemical tools to dissect CBP and p300 function. Curr Opin Chem Biol 45:195-203.

Breuillaud L, Rossetti C, Meylan EM, Mérinat C, Halfon O, Magistretti PJ, Cardinaux JR (2012) Deletion of CREB-regulated transcription coactivator 1 induces pathological aggression, depression-related behaviors, and neuroplasticity genes dysregulation in mice. Biol Psychiatry 72:528 536.

Castrén E, Berninger B, Leingärtner A, Lindholm D (1998) Regulation of brain-derived neurotrophic factor mRNA levels in hippocampus by neuronal activity. Prog Brain Res 117:57-64

Cha-Molstad H, Keller DM, Yochum GS, Impey S, Goodman RH (2004) Cell-type-specific binding of the transcription factor CREB to the cAMPresponse element. Proc Natl Acad Sci U S A 101:13572-13577.

Chen WG, West AE, Tao X, Corfas G, Szentirmay MN, Sawadogo M, Vinson C, Greenberg ME (2003) Upstream stimulatory factors are mediators of $\mathrm{Ca}^{2+}$-responsive transcription in neurons. J Neurosci 23:2572-2581.

Ch'ng TH, Uzgil B, Lin P, Avliyakulov NK, O’Dell TJ, Martin KC (2012) Activity-dependent transport of the transcriptional coactivator CRTC1 from synapse to nucleus. Cell 150:207-221. 
Conkright MD, Canettieri G, Screaton R, Guzman E, Miraglia L, Hogenesch JB, Montminy M (2003) TORCs: transducers of regulated CREB activity. Mol Cell 12:413-423.

Díaz-Ruiz C, Parlato R, Aguado F, Ureña JM, Burgaya F, Martínez A, Carmona MA, Kreiner G, Bleckmann S, Del Río JA, Schütz G, Soriano E (2008) Regulation of neural migration by the CREB/CREM transcription factors and altered Dab1 levels in CREB/CREM mutants. Mol Cell Neurosci 39:519-528.

Finkbeiner S, Tavazoie SF, Maloratsky A, Jacobs KM, Harris KM, Greenberg ME (1997) CREB: a major mediator of neuronal neurotrophin responses. Neuron 19:1031-1047.

Foulkes NS, Borrelli E, Sassone-Corsi P (1991) CREM gene: use of alternative DNA-binding domains generates multiple antagonists of cAMPinduced transcription. Cell 64:739-749.

Fukuchi M, Kirikoshi Y, Mori A, Eda R, Ihara D, Takasaki I, Tabuchi A, Tsuda M (2014) Excitatory GABA induces BDNF transcription via CRTC1 and phosphorylated CREB-related pathways in immature cortical cells. J Neurochem 131:134-146.

Fukuchi M, Tabuchi A, Kuwana Y, Watanabe S, Inoue M, Takasaki I, Izumi $\mathrm{H}$, Tanaka A, Inoue R, Mori H, Komatsu H, Takemori H, Okuno H, Bito H, Tsuda M (2015) Neuromodulatory effect of G $\alpha$ s- or G $\alpha q$-coupled G-protein-coupled receptor on NMDA receptor selectively activates the NMDA receptor $/ \mathrm{Ca}^{2+} /$ calcineurin/cAMP response element-binding protein-regulated transcriptional coactivator 1 pathway to effectively induce brain-derived neurotrophic factor expression in neurons. J Neurosci 35:5606-5624.

Govindarajan A, Rao BS, Nair D, Trinh M, Mawjee N, Tonegawa S, Chattarji S (2006) Transgenic brain-derived neurotrophic factor expression causes both anxiogenic and antidepressant effects. Proc Natl Acad Sci U S A 103:13208-13213.

Greenberg ME, Hermanowski AL, Ziff EB (1986) Effect of protein synthesis inhibitors on growth factor activation of c-fos, c-myc, and actin gene transcription. Mol Cell Biol 6:1050-1057.

Gundersen BB, Briand LA, Onksen JL, Lelay J, Kaestner KH, Blendy JA (2013) Increased hippocampal neurogenesis and accelerated response to antidepressants in mice with specific deletion of CREB in the hippocampus: role of cAMP response-element modulator $\tau$. J Neurosci 33:1367313685.

Hong EJ, McCord AE, Greenberg ME (2008) A biological function for the neuronal activity-dependent component of BDNF transcription in the development of cortical inhibition. Neuron 60:610-624.

Huang EJ, Reichardt LF (2001) Neurotrophins: roles in neuronal development and function. Annu Rev Neurosci 24:677-736.

Hughes P, Beilharz E, Gluckman P, Dragunow M (1993) Brain-derived neurotrophic factor is induced as an immediate early gene following $\mathrm{N}$-methyl-D-aspartate receptor activation. Neuroscience 57:319-328.

Hummler E, Cole TJ, Blendy JA, Ganss R, Aguzzi A, Schmid W, Beermann F, Schütz G (1994) Targeted mutation of the CREB gene: compensation within the CREB/ATF family of transcription factors. Proc Natl Acad Sci U S A 91:5647-5651.

Johannessen M, Delghandi MP, Moens U (2004) What turns CREB on? Cell Signal 16:1211-1227.

Kalvakolanu DV, Liu J, Hanson RW, Harter ML, Sen GC (1992) Adenovirus E1A represses the cyclic AMP-induced transcription of the gene for phosphoenolpyruvate carboxykinase (GTP) in hepatoma cells. J Biol Chem 267:2530-2536.

Kee BL, Arias J, Montminy MR (1996) Adaptor-mediated recruitment of RNA polymerase II to a signal-dependent activator. J Biol Chem 271: 2373-2375.

Kim TK, Hemberg M, Gray JM, Costa AM, Bear DM, Wu J, Harmin DA, Laptewicz M, Barbara-Haley K, Kuersten S, Markenscoff-Papadimitriou E, Kuhl D, Bito H, Worley PF, Kreiman G, Greenberg ME (2010) Widespread transcription at neuronal activity-regulated enhancers. Nature 465:182-187.

Koppel I, Timmusk T (2013) Differential regulation of BDNF expression in cortical neurons by class-selective histone deacetylase inhibitors. Neuropharmacology 75:106-115.

Koppel I, Tuvikene J, Lekk I, Timmusk T (2015) Efficient use of a translation start codon in BDNF exon I. J Neurochem 134:1015-1025.

Koppel I, Jaanson K, Klasche A, Tuvikene J, Tiirik T, Pärn A, Timmusk T (2018) Dopamine cross-reacts with adrenoreceptors in cortical astro- cytes to induce BDNF expression, CREB signaling and morphological transformation. Glia 66:206-216.

Kovács KA, Steullet P, Steinmann M, Do KQ, Magistretti PJ, Halfon O, Cardinaux JR (2007) TORC1 is a calcium- and cAMP-sensitive coincidence detector involved in hippocampal long-term synaptic plasticity. Proc Natl Acad Sci U S A 104:4700-4705.

Krylov D, Olive M, Vinson C (1995) Extending dimerization interfaces: the bZIP basic region can form a coiled coil. EMBO J 14:5329-5337.

Kuipers SD, Trentani A, Tiron A, Mao X, Kuhl D, Bramham CR (2016) BDNF-induced LTP is associated with rapid Arc/Arg3.1-dependent enhancement in adult hippocampal neurogenesis. Sci Rep 6:21222.

Kwok RP, Lundblad JR, Chrivia JC, Richards JP, Bächinger HP, Brennan RG, Roberts SG, Green MR, Goodman RH (1994) Nuclear protein CBP is a coactivator for the transcription factor CREB. Nature 370:223-226.

Laoide BM, Foulkes NS, Schlotter F, Sassone-Corsi P (1993) The functional versatility of CREM is determined by its modular structure. EMBO J 12:1179-1191.

Lauterborn JC, Rivera S, Stinis CT, Hayes VY, Isackson PJ, Gall CM (1996) Differential effects of protein synthesis inhibition on the activitydependent expression of BDNF transcripts: evidence for immediate-early gene responses from specific promoters. J Neurosci 16:7428-7436.

Lemberger T, Parkitna JR, Chai M, Schütz G, Engblom D (2008) CREB has a context-dependent role in activity-regulated transcription and maintains neuronal cholesterol homeostasis. FASEB J 22:2872-2879.

Li BX, Xiao X (2009) Discovery of a small-molecule inhibitor of the KIXKID interaction. Chembiochem 10:2721-2724.

Li S, Zhang C, Takemori H, Zhou Y, Xiong ZQ (2009) TORC1 regulates activity-dependent CREB-target gene transcription and dendritic growth of developing cortical neurons. J Neurosci 29:2334-2343.

Lonze BE, Ginty DD (2002) Function and regulation of CREB family transcription factors in the nervous system. Neuron 35:605-623.

Lu B, Nagappan G, Guan X, Nathan PJ, Wren P (2013) BDNF-based synaptic repair as a disease-modifying strategy for neurodegenerative diseases. Nat Rev Neurosci 14:401-416.

Lu B, Nagappan G, Lu Y (2014) BDNF and synaptic plasticity, cognitive function, and dysfunction. Handb Exp Pharmacol 220:223-250.

Lundblad JR, Kwok RP, Laurance ME, Harter ML, Goodman RH (1995) Adenoviral E1A-associated protein p300 as a functional homologue of the transcriptional co-activator CBP. Nature 374:85-88.

Luo Q, Viste K, Urday-Zaa JC, Senthil Kumar G, Tsai WW, Talai A, Mayo KE, Montminy M, Radhakrishnan I (2012) Mechanism of CREB recognition and coactivation by the CREB-regulated transcriptional coactivator CRTC2. Proc Natl Acad Sci U S A 109:20865-20870.

Mantamadiotis T, Lemberger T, Bleckmann SC, Kern H, Kretz O, Martin Villalba A, Tronche F, Kellendonk C, Gau D, Kapfhammer J, Otto C, Schmid W, Schütz G (2002) Disruption of CREB function in brain leads to neurodegeneration. Nat Genet 31:47-54.

Maynard KR, Hill JL, Calcaterra NE, Palko ME, Kardian A, Paredes D, Sukumar M, Adler BD, Jimenez DV, Schloesser RJ, Tessarollo L, Lu B, Martinowich K (2016) Functional role of BDNF production from unique promoters in aggression and serotonin signaling. Neuropsychopharmacology 41:1943-1955.

Maynard KR, Hobbs JW, Phan BN, Gupta A, Rajpurohit S, Williams C, Rajpurohit A, Shin JH, Jaffe AE, Martinowich K (2018) BDNF-TrkB signaling in oxytocin neurons contributes to maternal behavior. eLife 7:e33676.

Mayr B, Montminy M (2001) Transcriptional regulation by the phosphorylation-dependent factor CREB. Nat Rev Mol Cell Biol 2:599-609.

Messaoudi E, Ying SW, Kanhema T, Croll SD, Bramham CR (2002) Brainderived neurotrophic factor triggers transcription-dependent, late phase long-term potentiation in vivo. J Neurosci 22:7453-7461.

Messaoudi E, Kanhema T, Soulé J, Tiron A, Dagyte G, da Silva B, Bramham CR (2007) Sustained Arc/Arg3.1 synthesis controls long-term potentiation consolidation through regulation of local actin polymerization in the dentate gyrus in vivo. J Neurosci 27:10445-10455.

Minichiello L (2009) TrkB signalling pathways in LTP and learning. Nat Rev Neurosci 10:850-860.

Mioduszewska B, Jaworski J, Kaczmarek L (2003) Inducible cAMP early repressor (ICER) in the nervous system: a transcriptional regulator of neuronal plasticity and programmed cell death. J Neurochem 87:13131320.

Molina CA, Foulkes NS, Lalli E, Sassone-Corsi P (1993) Inducibility and 
negative autoregulation of CREM: an alternative promoter directs the expression of ICER, an early response repressor. Cell 75:875-886.

Nakajima S, Numakawa T, Adachi N, Ooshima Y, Odaka H, Yoshimura A, Kunugi H (2015) Self-amplified BDNF transcription is a regulatory system for synaptic maturation in cultured cortical neurons. Neurochem Int 91:55-61.

Nakajima T, Uchida C, Anderson SF, Parvin JD, Montminy M (1997) Analysis of a cAMP-responsive activator reveals a two-component mechanism for transcriptional induction via signal-dependent factors. Genes Dev 11:738-747.

Panja D, Kenney JW, D’Andrea L, Zalfa F, Vedeler A, Wibrand K, Fukunaga R, Bagni C, Proud CG, Bramham CR (2014) Two-stage translational control of dentate gyrus LTP consolidation is mediated by sustained BDNF-TrkB signaling to MNK. Cell Rep 9:1430-1445.

Papaleo F, Silverman JL, Aney J, Tian Q, Barkan CL, Chadman KK, Crawley JN (2011) Working memory deficits, increased anxiety-like traits, and seizure susceptibility in BDNF overexpressing mice. Learn Mem 18:534-544.

Park H, Poo MM (2013) Neurotrophin regulation of neural circuit development and function. Nat Rev Neurosci 14:7-23.

Parra-Damas A, Rubió-Ferrarons L, Shen J, Saura CA (2017) CRTC1 mediates preferential transcription at neuronal activity-regulated CRE/TATA promoters. Sci Rep 7:18004.

Pizzorusso T, Ratto GM, Putignano E, Maffei L (2000) Brain-derived neurotrophic factor causes cAMP response element-binding protein phosphorylation in absence of calcium increases in slices and cultured neurons from rat visual cortex. J Neurosci 20:2809-2816.

Pruunsild P, Kazantseva A, Aid T, Palm K, Timmusk T (2007) Dissecting the human BDNF locus: bidirectional transcription, complex splicing, and multiple promoters. Genomics 90:397-406.

Pruunsild P, Sepp M, Orav E, Koppel I, Timmusk T (2011) Identification of cis-elements and transcription factors regulating neuronal activitydependent transcription of human BDNF gene. J Neurosci 31:3295-3308.

Qyang Y, Luo X, Lu T, Ismail PM, Krylov D, Vinson C, Sawadogo M (1999) Cell-type-dependent activity of the ubiquitous transcription factor USF in cellular proliferation and transcriptional activation. Mol Cell Biol 19:1508-1517.

Saarelainen T, Vaittinen S, Castrén E (2001) trkB-receptor activation contributes to the kainate-induced increase in BDNF mRNA synthesis. Cell Mol Neurobiol 21:429-435.

Saura CA, Cardinaux JR (2017) Emerging roles of CREB-regulated transcription coactivators in brain physiology and pathology. Trends Neurosci 40:720-733.

Shieh PB, Hu SC, Bobb K, Timmusk T, Ghosh A (1998) Identification of a signaling pathway involved in calcium regulation of BDNF expression. Neuron 20:727-740.

Song Y, Zhai L, Valencia Swain J, Chen Y, Wang P, Chen L, Liu Y, Xiang S (2018) Structural insights into the CRTC2-CREB complex assembly on CRE. J Mol Biol 430:1926-1939.

Tabuchi A, Sakaya H, Kisukeda T, Fushiki H, Tsuda M (2002) Involvement of an upstream stimulatory factor as well as cAMP-responsive elementbinding protein in the activation of brain-derived neurotrophic factor gene promoter I. J Biol Chem 277:35920-35931.

Tao X, Finkbeiner S, Arnold DB, Shaywitz AJ, Greenberg ME (1998) $\mathrm{Ca}^{2+}$ influx regulates BDNF transcription by a CREB family transcription factor-dependent mechanism. Neuron 20:709-726.
Tejeda GS, Díaz-Guerra M (2017) Integral characterization of defective $\mathrm{BDNF} / \mathrm{TrkB}$ signalling in neurological and psychiatric disorders leads the way to new therapies. Int J Mol Sci 18:268.

Timmusk T, Palm K, Metsis M, Reintam T, Paalme V, Saarma M, Persson H (1993) Multiple promoters direct tissue-specific expression of the rat BDNF gene. Neuron 10:475-489.

Tuvikene J, Pruunsild P, Orav E, Esvald EE, Timmusk T (2016) AP-1 transcription factors mediate BDNF-positive feedback loop in cortical neurons. J Neurosci 36:1290-1305.

Tuvikene J (2018) CREB family transcription factors are major mediators of BDNF transcriptional autoregulation in cortical neurons - additional materials. Available at http://osf.io/4s28y/.

Uchida S, Teubner BJ, Hevi C, Hara K, Kobayashi A, Dave RM, Shintaku T, Jaikhan P, Yamagata $\mathrm{H}$, Suzuki T, Watanabe Y, Zakharenko SS, Shumyatsky GP (2017) CRTC1 nuclear translocation following learning modulates memory strength via exchange of chromatin remodeling complexes on the Fgfl gene. Cell Rep 18:352-366.

Vashishta A, Habas A, Pruunsild P, Zheng JJ, Timmusk T, Hetman M (2009) Nuclear factor of activated T-cells isoform c4 (NFATc4/NFAT3) as a mediator of antiapoptotic transcription in NMDA receptor-stimulated cortical neurons. J Neurosci 29:15331-15340.

Vilar M, Mira H (2016) Regulation of neurogenesis by neurotrophins during adulthood: expected and unexpected roles. Front Neurosci 10:26.

Walker WH, Daniel PB, Habener JF (1998) Inducible cAMP early repressor ICER down-regulation of CREB gene expression in sertoli cells. Mol Cell Endocrinol 143:167-178.

Wang L, Chang X, She L, Xu D, Huang W, Poo MM (2015) Autocrine action of BDNF on dendrite development of adult-born hippocampal neurons. J Neurosci 35:8384-8393.

Watts AG, Sanchez-Watts G, Liu Y, Aguilera G (2011) The distribution of messenger RNAs encoding the three isoforms of the transducer of regulated cAMP responsive element binding protein activity in the rat forebrain. J Neuroendocrinol 23:754-766.

West AE, Pruunsild P, Timmusk T (2014) Neurotrophins: transcription and translation. Handb Exp Pharmacol 220:67-100.

Wibrand K, Messaoudi E, Håvik B, Steenslid V, Løvlie R, Steen VM, Bramham CR (2006) Identification of genes co-upregulated with arc during BDNF-induced long-term potentiation in adult rat dentate gyrus in vivo. Eur J Neurosci 23:1501-1511.

Willems E, Leyns L, Vandesompele J (2008) Standardization of real-time PCR gene expression data from independent biological replicates. Anal Biochem 379:127-129.

Yasuda M, Fukuchi M, Tabuchi A, Kawahara M, Tsuneki H, Azuma Y, Chiba Y, Tsuda M (2007) Robust stimulation of TrkB induces delayed increases in BDNF and arc mRNA expressions in cultured rat cortical neurons via distinct mechanisms. J Neurochem 103:626-636.

Ying SW, Futter M, Rosenblum K, Webber MJ, Hunt SP, Bliss TV, Bramham CR (2002) Brain-derived neurotrophic factor induces long-term potentiation in intact adult hippocampus: requirement for ERK activation coupled to CREB and upregulation of arc synthesis. J Neurosci 22:1532-1540.

Zhou Y, Wu H, Li S, Chen Q, Cheng XW, Zheng J, Takemori H, Xiong ZQ (2006) Requirement of TORC1 for late-phase long-term potentiation in the hippocampus. PLoS One 1:e16.

Zuccato C, Cattaneo E (2009) Brain-derived neurotrophic factor in neurodegenerative diseases. Nat Rev Neurol 5:311-322. 